\title{
Relative Growth of the Limbs and Trunk in Sifakas: Heterochronic, Ecological, and Functional Considerations
}

\author{
MATTHEW J. RAVOSA, DAVID M. MEYERS, \\ AND KENNETH E. GLANDER \\ Department of Cell, Molecular and Structural Biology, Northwestern \\ University Medical School, Chicago, Illinois 60611 (M.J.R.); Department \\ of Biological Anthropology and Anatomy (D.M.M., K.E.G.) and Duke \\ University Primate Center (K.E.G.), Duke University, Durham, North \\ Carolina 27706
}

KEY WORDS Propithecus, Allometry/scaling, Heterochrony, Ontogeny, Body proportions, Ecogeographic size variation, Sexual dimorphism

ABSTRACT Limb, trunk, and body weight measurements were obtained for growth series of Milne-Edwards's diademed sifaka, Propithecus diadema edwardsi, and the golden-crowned sifaka, Propithecus tattersalli. Similar measures were obtained also for primarily adults of two subspecies of the western sifaka: Propithecus verreauxi coquereli, Coquerel's sifaka, and Propithecus verreauxi verreauxi, Verreaux's sifaka. Ontogenetic series for the larger-bodied $P$. $d$. edwardsi and the smaller-bodied $P$. tattersalli were compared to evaluate whether species-level differences in body proportions result from the differential extension of common patterns of relative growth. In bivariate plots, both subspecies of $P$. verreauxi were included to examine whether these taxa also lie along a growth trajectory common to all sifakas.

Analyses of the data indicate that postcranial proportions for sifakas are ontogenetically scaled, much as demonstrated previously with cranial dimensions for all three species (Ravosa, 1992). As such, $P$. d. edwardsi apparently develops larger overall size primarily by growing at a faster rate, but not for a longer duration of time, than $P$. tattersalli and $P$. verreauxi; this is similar to results based on cranial data. A consideration of Malagasy lemur ecology suggests that regional differences in forage quality and resource availability have strongly influenced the evolutionary development of body-size variation in sifakas. On one hand, the rainforest environment of $P$. $d$. edwardsi imposes greater selective pressures for larger body size than the dry-forest environment of $P$. tattersalli and $P$. v. coquereli, or the semi-arid climate of $P . v$. verreauxi. On the other hand, as progressively smaller-bodied adult sifakas are located in the east, west, and northwest, this apparently supports suggestions that adult body size is set by dry-season constraints on food quality and distribution (i.e., smaller taxa are located in more seasonal habitats such as the west and northeast). Moreover, the fact that body-size differentiation occurs primarily via differences in growth rate is also due apparently to differences in resource seasonality (and juvenile mortality risk in turn) between the eastern rainforest and the more temperate northeast and west.

Most scaling coefficients for both arm and leg growth range from slight negative allometry to slight positive allometry. Given the low intermembral

\footnotetext{
Received June 25, 1992; accepted June 28, 1993

Address reprint requests to Dr. Matthew J. Ravosa, Department of CMS Biology, Northwestern University Medical School, 303 E. Chicago Ave., Chicago, IL 60611-3008.
} 
index for sifakas, which is also an adaptation for propulsive hindlimb-dominated jumping, this suggests that differences in adult limb proportions are largely set prenatally rather than being achieved via higher rates of postnatal hindlimb growth. Our analyses further indicate that the larger-bodied $P$. $d$. edwardsi has a higher adult intermembral index than $P$. tattersalli and $P$. verreauxi, thus supporting the allometric argument regarding the interspecific scaling of limb proportions in arboreal primates which employ vertical postures (Cartmill, 1974, 1985; Jungers, 1978, 1985).

Lastly, additional analyses indicate that $P$. d. edwardsi exhibits significant sexual dimorphism where adult females are larger than adult males in about one-third of all adult comparisons, whereas $P$. tattersalli exhibits significant sexual dimorphism in about one-fifth of all adult comparisons. Among western sifakas, adult $P$. v. coquereli exhibit significant sex dimorphism in about one-third of all comparisons, whereas adult $P$. $v$. verreauxi show no significant differences between the sexes. Given that all taxa are ontogenetically scaled, this suggests that sexual dimorphism develops via such processes as well. Interestingly, our data indicate that sex dimorphism is allometric, with larger-bodied taxa like $P$. d. edwardsi being more dimorphic.

(1) 1993 Wiley-Liss, Inc.

A number of recent allometric and heterochronic analysis have contributed much to our understanding of the developmental processes underlying patterns of ecogeographic size variation and phyletic size change in closely related primates. In Malagasy lemurs, Ravosa (1992) demonstrates that interspecific differences in adult skull form among all three sifakas result from the differential extension of common patterns of allometric or relative growth. In other words, sifaka cranial morphology is ontogenetically scaled (sensu Gould, 1975) (Fig. 1). Little is known about ontogenetic scaling in the postcranium of these primates, despite that such methods are equally suited to addressing questions about locomotor form and function.

In fact, apart from several early studies regarding ontogenetic scaling of the anthropoid axial skeleton (e.g., Lumer, 1939; Lumer and Schultz, 1941, 1947), similar allometric approaches to primate postcranial morphology have been rare outside of the previous decade (e.g., Jungers and Fleagle, 1980; Shea, 1981, 1984, 1992; Buschang, 1982; Jungers and Susman, 1984; Jungers et al., 1988; Jungers and Hartman, 1988; Falsetti and Cole, 1992; Gomez, 1992, in press; Jungers and Cole, 1992). Moreover, except for Gomez's (1992, in press) studies on growth and proportions of the limbs and trunk in lorisines, no other studies exist for strepsirhine primates. This is surprising because many strepsirhine congeners vary considerably in body size (e.g., Albrecht et al., 1990; Kappeler, 1990, 1991; Glander et al., 1992; Ravosa, 1992; Godfrey et al., 1993).

Given a pervasive pattern of ontogenetic scaling in two taxa of differing adult sizes, there are two options for the larger species to evolve a larger terminal body size relative to the hypothetically ancestral or primitive condition of the smaller species ${ }^{1}$. This is commonly referred to as phyletic gigantism or peramorphosis via hypermorphosis (Gould, 1977; Shea 1983, 1988). First, one can examine rate of growth-in-time to determine whether the larger taxon grows faster via rate hypermorphosis. That is, individuals of the larger species develop progressively larger limb and trunk measures but mature at the same chronological age as those of the smaller taxon (Fig. 2A). Second, one can examine time of growth shut off to distinguish whether the larger taxon grows

\footnotetext{
${ }^{1}$ These scenarios assume no dissociation of allometric trajectories between species as is characterized in the processes of acceleration or neoteny (Shea, 1983, 1988). Finally, these scenarios do not assume necessarily that both species have the same neonatal size, just that absolute differences in neonatal body size between species will be considerably less than interspecific differences in adult body size.
} 


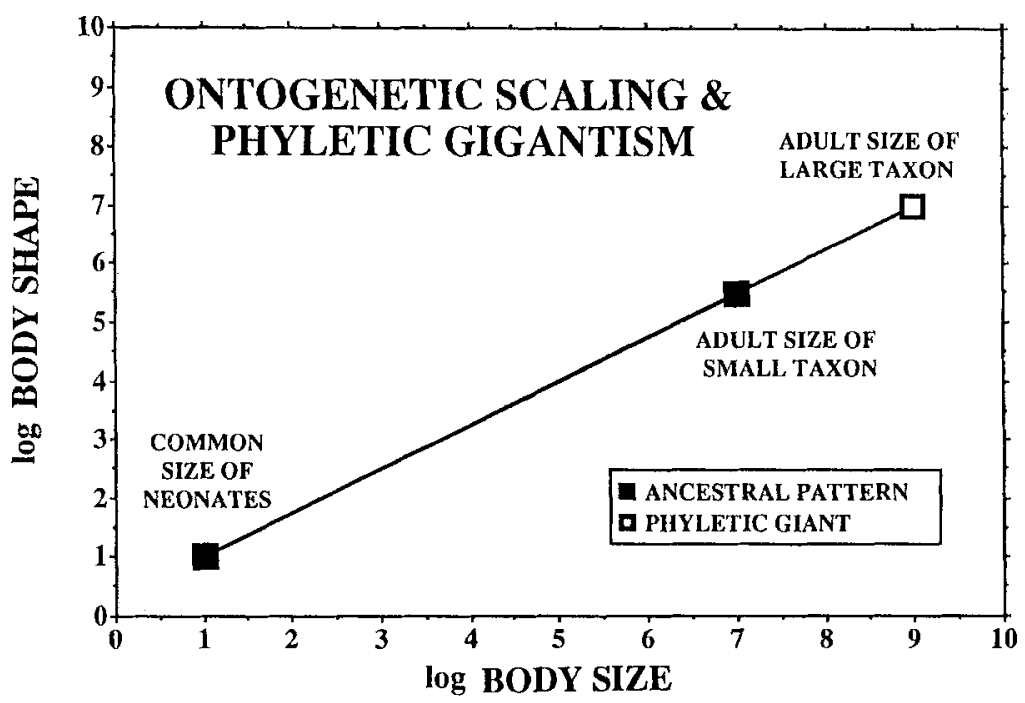

Fig. 1. Growth trajectories for a measure of body shape vs. a measure of body size for two closely related species of differing adult sizes. Both taxa have similar growth allometries, such that morphological differences between adults of each species are due to the differential extension of shared patterns of relative growth (smaller-bodied taxon $=$ solid square; larger-bodied taxon $=$ open square).

for a longer duration via time hypermorphosis. That is, members of the larger species have similarly sized extremities at the same subadult age as those of the smaller species but mature at a later chronological age (Fig. 2B) (Shea 1983, 1988) ${ }^{2}$. Although considered separately, it would be evident that both heterochronic processes affected the evolution of species differences in postcranial dimensions if developmental modifications occur early in ontogeny and become especially marked in later stages.

As a point of clarification, although the body size and ontogenetic trajectory of the smaller species may approximate more closely the ancestral or primitive pattern, this is not always the case. Phyletic dwarfing or paedomorphosis via ontogenetic scaling would be an obvious exception to the scenario detailed above (Gould, 1977; Shea $1983,1988)$. In cases where the larger body size more closely represents the primitive condition, the heterochronic terminology alters accordingly. Rate hypomorphosis refers

\footnotetext{
${ }^{2} \mathrm{As}$ used in this context, faster (rate) and longer (time) characterizations refer to growth-in-time, not to different coefficients (regression slopes) of relative or allometric growth.
}

to cases where the smaller-bodied taxon matures at the same chronological age but grows at a slower rate than the larger-bodied taxon. Time hypomorphosis refers to cases where the smaller-bodied taxon grows at the same rage but for a shorter duration (Shea, 1983, 1988). As the polarity of size change among sifakas is presently unknown, for the purposes of this study we utilize terminology detailed in the previous paragraph.

In this study, allometric analyses are applied to ontogenetic series representing two Malagasy primates of differing adult body size: Propithecus diadema edwardsi $(5,837$ g), Milne-Edwards's diademed sifaka from the rainforest of Ranomafana, and Propithecus tattersalli $(3,493 \mathrm{~g})$, the golden-crowned sifaka (Simons, 1988) from the dry forest of Daraina. The growth series are also compared to mostly adult data for two subspecies of Propithecus verreauxi, the western sifaka: Propithecus verreauxi coquereli (3,992 g), Coquerel's sifaka from the dry forest of Ankijabe and Propithecus verreauxi verreauxi (3,098 g), Verreaux's sifaka from the semi-arid forest of Bevola (Glander and Simons, in preparation). The allometric fo- 

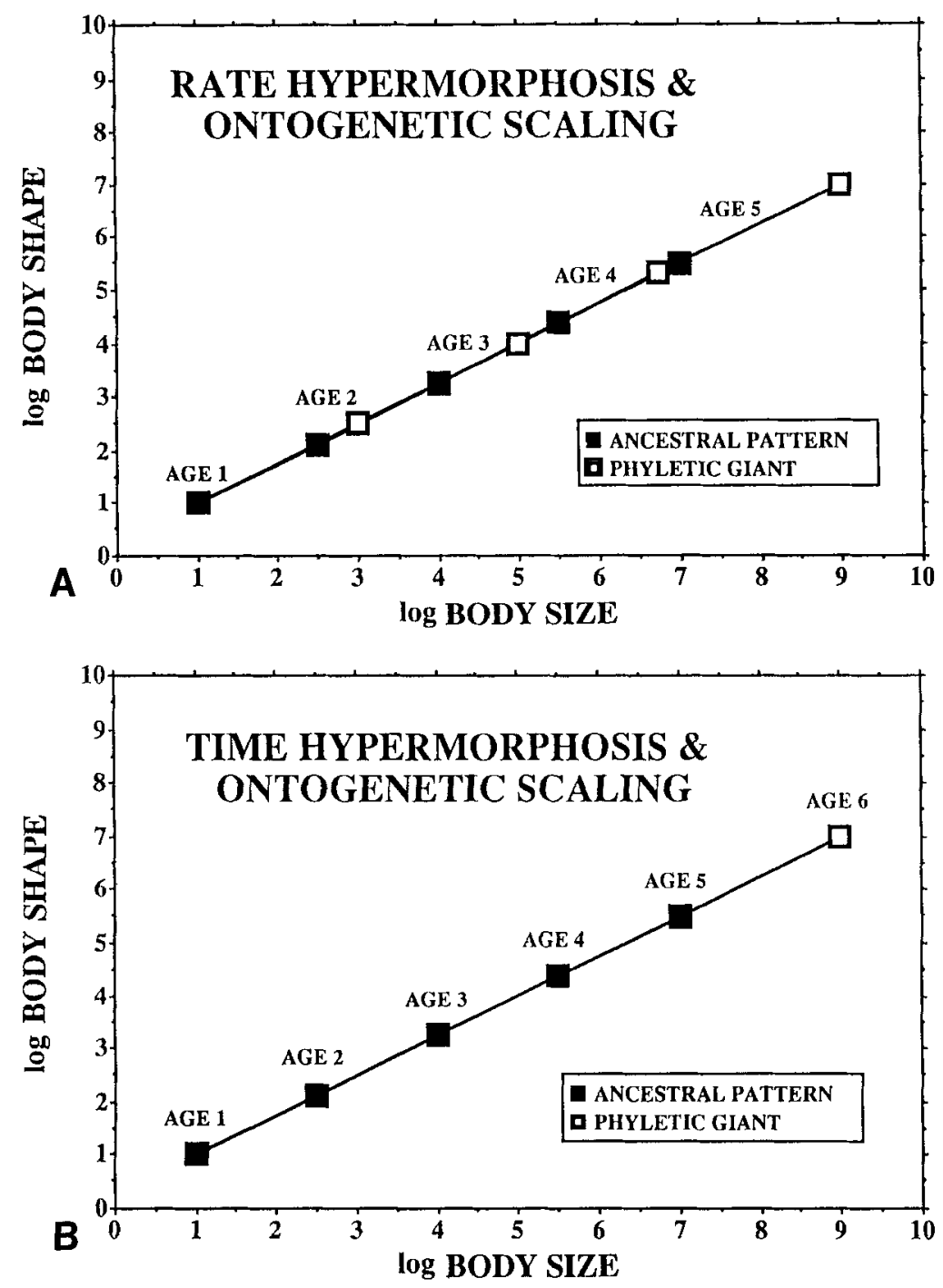

Fig. 2. A larger-bodied species and a smaller-bodied species share similar growth trajectories for a measure of body shape vs. body size. The larger species can extend the smaller species' ontogenetic scaling trend to develop larger adult sizes in two manners. First, the larger species can grow faster via rate hypermorphosis (i.e., individuals of the same age are dissimilar in size but grow for the same amount of time) (A). Second, the larger species can also grow longer via time hypermorphosis (i.e., individuals of the same age are similar in size but grow for different durations) (B). On the other hand, if the growth pattern of the smaller species represents the derived condition, then the two heterochronic processes would be characterized, respectively, as rate and time hypomorphosis.

cus of this study is fourfold: to evaluate whether differences in limb and trunk proportions among congeners of differing body size develop via ontogenetic scaling; to address, given a pervasive pattern of ontogenetic scaling of postcranial and cranial (Ra- vosa, 1992) morphology in sifakas, whether size differences among taxa develop via rate hypermorphosis, with $P$. $d$. edwardsi growing faster, and/or time hypermorphosis, with $P$. d. edwardsi growing longer; to describe the functional implications of limb 
and trunk growth in three species of vertical clingers and leapers; and lastly to highlight the important link between patterns of intra- and interspecific scaling in the extremities (e.g., Shea, 1981).

Considered more broadly, a heterochronic analysis of the relative growth of sifaka body proportions has direct implications for models which stress the importance of ecological factors in the evolution of primate body size differences (e.g., Terborgh and van Schaik, 1987; Albrecht et al., 1990). Therefore, another major focus of this study will be the ecological bases of size differentiation in sifakas, since Milne-Edwards's sifaka inhabits a rainforest environment, whereas the golden-crowned sifaka and the western sifaka inhabit a dry-forest or semi-arid climate. Lastly, this study will provide additional data regarding sexual dimorphism in sifakas, where adult females are larger than adult males (Kappeler, 1990, 1991; Jenkins and Albrecht, 1991; Glander et al., 1992; Ravosa, 1992; Godfrey et al., 1993). As such, comparisons within and among these taxa will further detail the developmental underpinnings of ecogeographic and sexual differentiation in sifakas.

\section{MATERIALS AND METHODS Samples}

The ontogenetic sample of Milne-Edwards's diademed sifaka, Propithecus diadema edwardsi, consists of 21 individuals (13 adults, 8 non-adults) that were trapped and measured in the Ranomafana rainforest of southeast Madagascar by K.E.G. (May 1987, 1988, 1989). The ontogenetic sample of the golden-crowned sifaka, Propithecus tattersalli, consists of 40 individuals (18 adults, 22 non-adults) that were trapped and measured in the Daraina dry forest of northeast Madagascar by D.M.M. (1989, 1990). Limited body weight data from birth to adulthood for one P. tattersalli at the Duke University Primate Center (DUPC) were also included. Adult data for two subspecies of the western sifaka, Propithecus verreauxi, were also obtained. The sample of Coquerel's sifaka, Propithecus verreauxi coquereli, consists of 15 adults that were trapped and measured in the Ankijabe dry forest of northwest Madagascar by K.E.G. (1982, 1984). Additional limited ontogenetic data on body weight for 16 P. v. coquereli at the DUPC were also considered, although in only two cases do the data range from birth to adulthood. The sample of Verreaux's sifaka, Propithecus verreauxi verreauxi, consists of seven adults that were trapped and measured in the Bevola semi-arid forest of southwest Madagascar by K.E.G. (1984). In all three species, several individuals were measured more than once, such as at different times of the year or in successive years; therefore the growth series constitute mixed-cross-sectional samples (Cock, 1966).

For between-species comparisons of sifaka somatic development, the data are grouped into six age classes based on halfyear or yearly intervals as well as data availability: $\quad 1=0-6$ months; $2=6$ months-1.5 years; $3=1.5-2.5$ years; $4=2.5-4$ years; $5=4-5$ years; $6=5+$ years (adult). Chronological age for animals in age classes 1-3 was often figured directly or easily determined due to the highly seasonal nature of sifaka birth patterns. For older animals in age classes 4-6, the chronological age of several adults was estimated from tooth wear (Glander et al., 1992). In $P$. tattersalli there are at least four cases per age classes $1-5$. The $P$. $d$. edwardsi sample has at least four cases per age classes 1 and 5 , only two cases for age classes 2 and 4 , and three cases for age class 3 .

\section{Measurements}

Most morphometric data were obtained from individuals sedated and trapped in the field. Body weights were taken by suspending infants from a $1 \mathrm{~kg}$ portable spring scale and adults from a $20 \mathrm{~kg}$ portable spring scale; weights were recorded to within $10 \mathrm{~g}$ (Glander et al., 1991, 1992). Neonate and infant body weight data for $P$. tattersalli and $P . v$. coquereli at the DUPC were collected using a $1 \mathrm{~kg}$ triple-beam scale; no other data were available for DUPC sifakas. In addition to body weight, eight linear and three circumferential measures were taken on wild-caught animals (See Appendix A at end of text). These data were recorded to the nearest millimeter with a 3 meter metal tape and are defined according to Glander et 


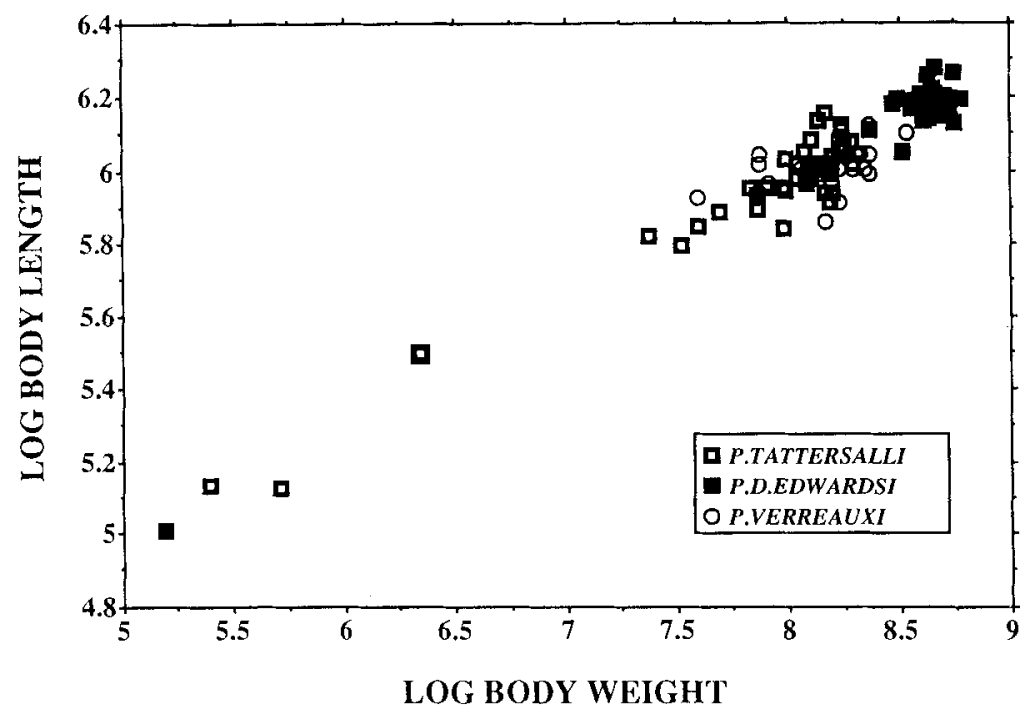

Fig. 3. A plot of $\log _{\mathrm{e}}$ body length (mm) vs. $\log _{\mathrm{e}}$ body weight $(\mathrm{g})$. Note that the growth series for all three sifakas species are coincidental, such that morphological differences between adults are due to the differential extension of shared scaling patterns. This typifies the majority of sifaka comparisons.

al. (1991, 1992). Three additional linear measures were derived from the original data: body length, arm length, and leg length. Upper arm and thigh circumference were not collected for western sifakas.

\section{Statistical analyses}

Within both ontogenetic series, leastsquares and reduced major-axis bivariate regression analyses $(P<0.05)$ were applied to log-transformed morphogenic data to describe allometric growth trajectories. Following Sokal and Rohlf (1981), the standard error of the least-squares slope is used for the reduced major-axis slope as well. For regression analyses in both growth series the data were averaged by age class and sex, in large part so as to reduce the effects of disproportionately large numbers of cases in a particular age class or sex on the slope of the regression line. For example, since adults lie at one end of the size range, greater numbers of adults would bias the calculation of the regression line and thereby potentially result in a lower regression coefficient. To be sure, it is possible that grouping the data by age group may mask more complex allometric patterns; visual inspections using indi- vidual values suggest that this may not be a major consideration for sifakas (e.g., Figs. $3-6)$.

Body weight was used as the independent variable in most bivariate comparisons, although several additional comparisons were made, such as arm length vs. leg length. While isometry in bivariate comparisons between linear measures is a slope value of 1.00 , in cases where linear measures are regressed against body weight isometry equals 0.33 . When a circumferential measure is compared to body weight an isometric slope equals 0.67 , and when a circumferential measure is compared to a linear measure isometry equals a value of 2.00 . Analysis of covariance (ANCOVA) $(P<$ 0.05 ) was used to test for differences in patterns of relative growth between leastsquares regression lines derived for each growth series, namely whether sifakas are ontogenetically scaled.

As only adult limb and trunk data are available for both $P$. v. coquereli and $P$. $v$. verreauxi, an alternative method was used to assess whether these taxa are ontogenetically scaled versions of $P$. d. edwardsi and $P$. tattersalli. In this case, if the postcranial 


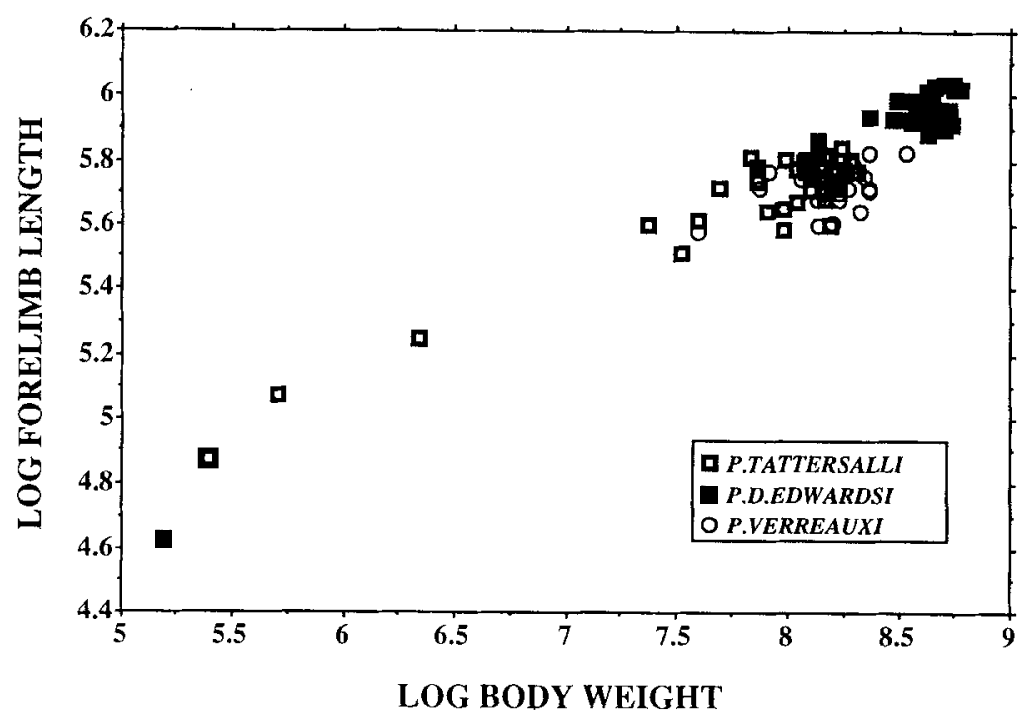

Fig. 4. A plot of $\log _{e}$ forelimb length vs. $\log _{e}$ body weight. As in most comparisons, the ontogenetic scaling trajectory for Milne-Edwards's sifaka, that for the golden-crowned sifaka, and the adult data for both subspecies of the western sifaka are coincidental.

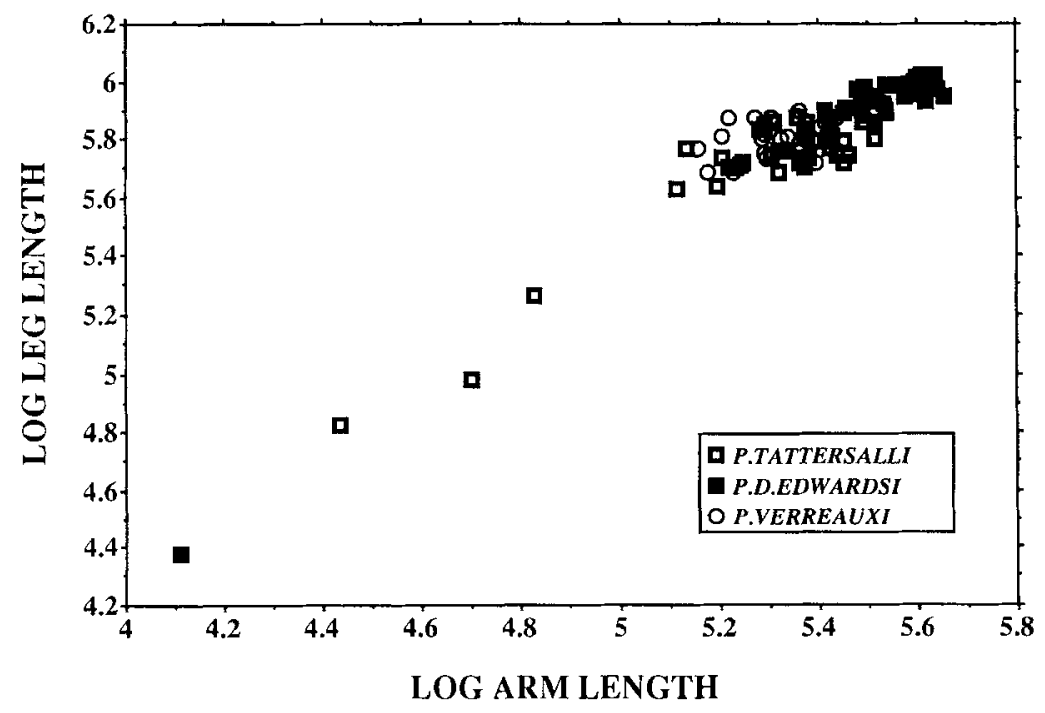

Fig. 5. A plot of $\log _{e}$ leg length vs. $\log _{e}$ arm length. Again, the data for all three species lie along a common ontogenetic trajectory.

growth trajectories for Milne-Edwards's sifaka and/or the golden-crowned sifaka intersect the adult scatter for either subspecies of the western sifaka, then it is most parsimonious to infer that these forms are ontoge- netically scaled (see Ravosa, 1992; Shea, 1992; also Jungers and Cole, 1992). However, if the adult data scatter fall mostly above or below the regression line, then it is inferred that morphological differences be- 


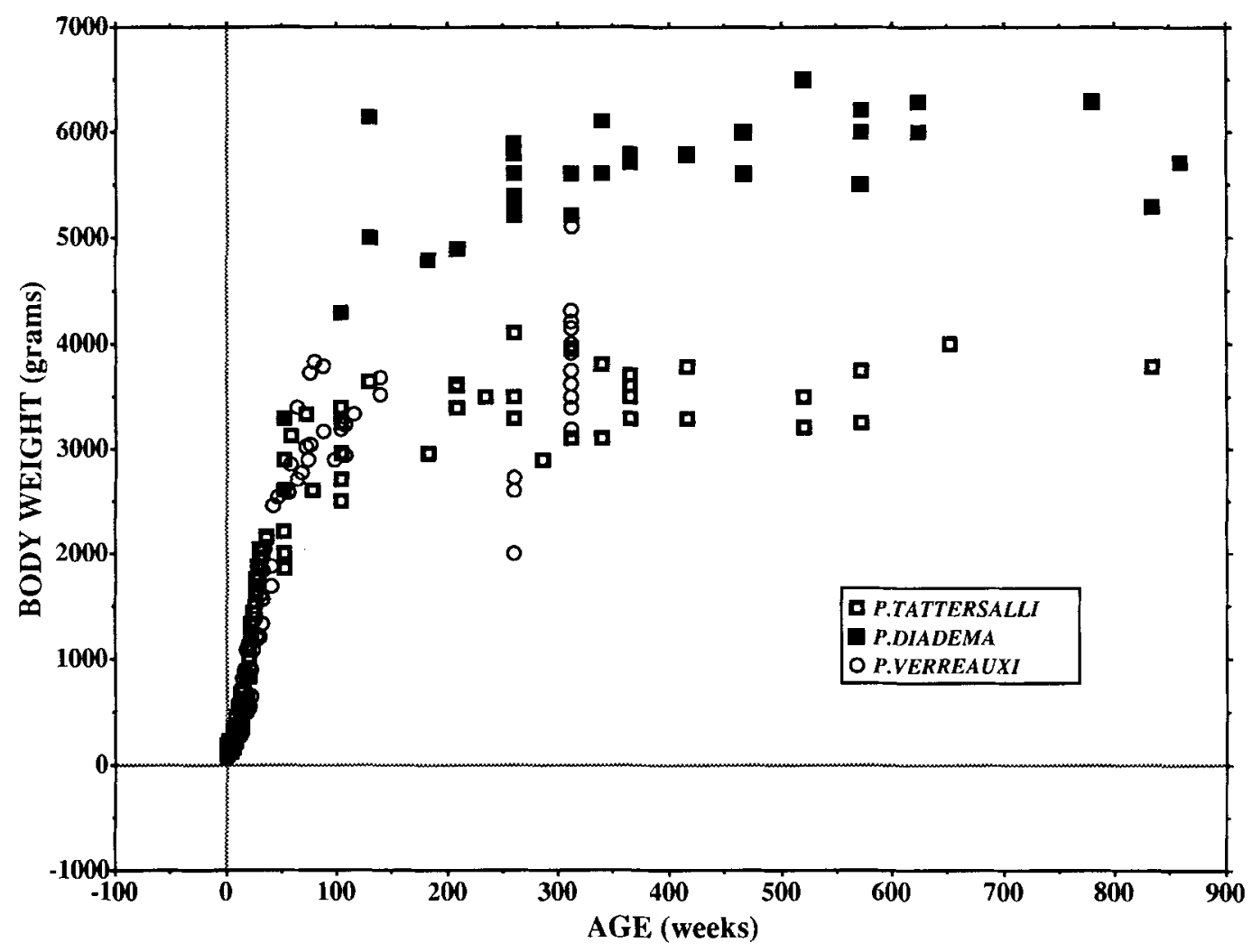

Fig. 6. A plot of body weight vs. age (weeks). Note that individual wild-caught and DUPC data for all taxa lie along the same growth curve early in ontogeny. Sifaka growth patterns differ only at later ontogenetic stages due to terminal differentiation in adult body size among species.

tween adults of each sister taxon do not result from the differential extension of common patterns of relative growth.

T-tests $(P<0.05)^{3}$ were used to examine species and sex differences in postcranial dimensions at similar age classes. For instance, given a pervasive pattern of ontogenetic scaling among sifakas, if at common age classes subadult means for each variable are significantly different, then this

\footnotetext{
${ }^{3}$ In both between-species and between-sex analyses, comparisons are made with "original" measures (e.g., tail length), "original composite" measures (e.g., tail-crown length), and "derived" measures (e.g., body length). This may lead to a potential bias in accepting greater numbers of significant or non-significant comparisons, as the original composite and/or derived measures may not necessarily vary independent of the original measures. In this study, such a pattern does not seem to characterize the majority of sifaka comparisons.
}

would indicate that species differences in body size develop via rate hypermorphosis (Shea, 1983, 1988); that is, the larger-bodied Milne-Edwards's sifaka grows at a faster rate, but not for a longer period of time than the golden-crowned sifaka (Ravosa, 1992). On the other hand, if species differences are noted only between adult sifakas, then this would indicate that morphological differences develop via time hypermorphosis (Shea, 1983, 1988); that is, Milne-Edwards's sifaka grows for a longer duration, but not at a faster rate than the smaller-bodied goldencrowned sifaka (Ravosa, 1992). These patterns of growth increases are not mutually exclusive, however. For example, if slight body-size differences are noted early in ontogeny and are more marked between adult sifakas, then this would suggest that size differentiation evolved by $P . d$. edwardsi 
TABLE 1. Propithecus tattersalli bivariate regression analyses

\begin{tabular}{|c|c|c|c|c|}
\hline Vs. body weight ${ }^{1-3}$ & Y-int & Slope & $95 \% \mathrm{CI}$ & $r$ \\
\hline \multirow[t]{2}{*}{ Body length } & 3.397 & 0.320 & \pm 0.025 & 0.974 \\
\hline & 3.328 & 0.329 & & \\
\hline \multirow[t]{2}{*}{ Tail-crown length } & 4.063 & 0.330 & \pm 0.024 & 0.976 \\
\hline & 4.003 & 0.338 & & \\
\hline \multirow[t]{2}{*}{ Tail length } & 3.387 & 0.334 & \pm 0.033 & 0.958 \\
\hline & 3.268 & 0.349 & & \\
\hline \multirow[t]{2}{*}{ Chest circumference } & 2.600 & 0.374 & \pm 0.037 & 0.958 \\
\hline & $\begin{array}{l}2.473 \\
3.226\end{array}$ & $\begin{array}{l}0.390 \\
0.312\end{array}$ & \pm 0.022 & \\
\hline Forelimb length & $\begin{array}{l}3.226 \\
3.175\end{array}$ & 0.319 & \pm 0.022 & 0.979 \\
\hline \multirow[t]{2}{*}{ Forefoot length } & 2.334 & 0.282 & \pm 0.021 & 0.977 \\
\hline & 2.279 & 0.289 & & \\
\hline \multirow{2}{*}{ Arm length } & 2.719 & 0.327 & \pm 0.024 & 0.977 \\
\hline & 2.660 & 0.335 & & \\
\hline \multirow[t]{2}{*}{ Thumb length } & 1.127 & 0.337 & \pm 0.023 & 0.980 \\
\hline & 1.075 & 0.344 & & \\
\hline \multirow[t]{2}{*}{ Upper arm circumference } & 1.667 & 0.371 & \pm 0.042 & 0.946 \\
\hline & 1.503 & 0.392 & & \\
\hline \multirow[t]{2}{*}{ Hindlimb length } & 3.716 & 0.300 & \pm 0.018 & 0.984 \\
\hline & 3.674 & 0.305 & & \\
\hline \multirow{2}{*}{ Hindfoot length } & 2.712 & 0.276 & \pm 0.025 & 0.966 \\
\hline & 2.632 & 0.286 & & \\
\hline Leg length & 3.270 & 0.310 & \pm 0.018 & 0.985 \\
\hline \multirow{2}{*}{ Big-toe length } & 3.234 & 0.315 & +0023 & 0961 \\
\hline & $\begin{array}{l}2.495 \\
2.418\end{array}$ & $\begin{array}{l}0.235 \\
0.245\end{array}$ & \pm 0.023 & 0.001 \\
\hline \multirow[t]{2}{*}{ Thigh circumference } & 1.433 & 0.460 & \pm 0.019 & 0.992 \\
\hline & 1.389 & 0.466 & & \\
\hline \multirow[t]{2}{*}{ Forelimb vs. hindlimb length } & -0.607 & 1.036 & \pm 0.055 & 0.988 \\
\hline & -0.687 & 1.049 & & \\
\hline \multirow[t]{2}{*}{ Arm length vs. leg length } & -0.684 & 1.047 & \pm 0.064 & 0.984 \\
\hline & -0.782 & 1.064 & & \\
\hline \multirow[t]{2}{*}{ Upper arm vs. thigh circumference } & 0.531 & 0.802 & \pm 0.089 & 0.949 \\
\hline & 0.315 & 0.845 & & \\
\hline \multirow[t]{2}{*}{ Upper arm vs. arm length } & -1.526 & 1,112 & \pm 0.150 & 0.923 \\
\hline & -1.793 & 1.205 & & \\
\hline \multirow[t]{2}{*}{ Thigh circumference vs. leg length } & -3.274 & 1.458 & \pm 0.070 & 0.990 \\
\hline & -3.359 & 1.473 & & \\
\hline
\end{tabular}

${ }^{1}$ All of the regression analyses are performed on pooled-sex samples.

${ }^{2}$ Most regression slopes are significantly different from zero at $P<0.01$; the rest are significant at $P<0.05$.

${ }^{3}$ In all bivariate comparisons, least-squares regression analyses are indicated on the first line, while reduced major-axis regression analyses are indicated second.

growing both faster and for a longer period of time.

\section{RESULTS}

\section{Ontogenetic scaling in sifakas}

In Propithecus tattersalli all 14 bivariate regressions vs. body weight, as well as the five additional comparisons, are highly correlated (Table 1). In Propithecus diadema edwardsi all 14 bivariate regressions vs. body weight, as well as the five additional comparisons, are moderately to highly correlated (Table 2). The regression coefficients for both species typically indicate slight negative allometry to slight positive allometry for most limb and trunk measures. In 17 of 19 cases, between-species comparisons (ANCOVAs) of postcranial growth patterns are not significantly different between $P$. tattersalli and P. d. edwardsi (Table 3). When the mostly adult data for Propithecus verreauxi coquereli and Propithecus verreauxi verreauxi are plotted with the two growth series, 12 of 14 comparisons likewise cluster along common scaling trajectories (Table 3; Figs. 3-6). Among all three species, the cases that do not indicate ontogenetic scaling are hindfoot length (Fig. 7) and tail length (Fig. 8) vs. body weight (Table 3). Therefore, the vast majority of morphologi- 
TABLE 2. Propithecus diadema edwardsi bivariate regression analyses

\begin{tabular}{|c|c|c|c|c|}
\hline Vs. body weight ${ }^{1-3}$ & Y-int & Slope & $95 \% \mathrm{CI}$ & $\mathbf{r}$ \\
\hline \multirow[t]{2}{*}{ Body length } & 3.323 & 0.330 & \pm 0.012 & 0.994 \\
\hline & 3.308 & 0.332 & & \\
\hline \multirow[t]{2}{*}{ Tail-crown length } & 3.730 & 0.362 & \pm 0.013 & 0.995 \\
\hline & 3.714 & 0.364 & & \\
\hline \multirow[t]{2}{*}{ Tail length } & 2.695 & 0.400 & \pm 0.022 & 0.988 \\
\hline & 2.657 & 0.405 & & \\
\hline \multirow[t]{2}{*}{ Chest circumference } & 1.953 & 0.451 & \pm 0.088 & 0.889 \\
\hline & 1.479 & 0.507 & & \\
\hline \multirow[t]{2}{*}{ Forelimb length } & 2.697 & 0.381 & \pm 0.012 & 0.996 \\
\hline & 2.678 & 0.383 & & \\
\hline \multirow[t]{2}{*}{ Forefoot length } & 2.001 & 0.337 & \pm 0.009 & 0.997 \\
\hline & 2.991 & 0.338 & & \\
\hline \multirow[t]{2}{*}{ Arm length } & 2.054 & 0.407 & \pm 0.017 & 0.993 \\
\hline & 2.027 & 0.410 & & \\
\hline \multirow{2}{*}{ Thumb length } & 1.462 & 0.309 & \pm 0.025 & 0.975 \\
\hline & 1.406 & 0.316 & & \\
\hline \multirow[t]{2}{*}{ Upper arm circumference } & 2.482 & 0.284 & \pm 0.105 & 0.715 \\
\hline & 1.524 & 0.397 & & \\
\hline \multirow[t]{2}{*}{ Hindlimb length } & 2.945 & 0.395 & \pm 0.013 & 0.996 \\
\hline & 2.927 & 0.397 & & \\
\hline \multirow[t]{2}{*}{ Hindfoot length } & 2.551 & 0.306 & \pm 0.012 & 0.994 \\
\hline & 2.534 & 0.308 & & \\
\hline \multirow[t]{2}{*}{ Leg length } & 2.122 & 0.447 & \pm 0.015 & 0.996 \\
\hline & 2.104 & 0.449 & & \\
\hline \multirow[t]{2}{*}{ Big-toe length } & 1.629 & 0.352 & \pm 0.018 & 0.990 \\
\hline & 1.593 & 0.356 & & \\
\hline \multirow[t]{2}{*}{ Thigh circumference } & 1.295 & 0.474 & \pm 0.048 & 0.967 \\
\hline & 1.159 & 0.490 & & \\
\hline \multirow[t]{2}{*}{ Forelimb vs. hindlimb length } & -0.136 & 0.963 & \pm 0.015 & 0.999 \\
\hline & -0.142 & 0.964 & & \\
\hline \multirow[t]{2}{*}{ Arm length vs. leg length } & 0.123 & 0.910 & \pm 0.021 & 0.998 \\
\hline & 0.112 & 0.912 & & \\
\hline \multirow[t]{2}{*}{ Upper arm vs. thigh circumference } & 1.678 & 0.604 & \pm 0.204 & 0.746 \\
\hline & 0.586 & 0.810 & & \\
\hline \multirow[t]{2}{*}{ Upper arm vs. arm length } & -1.907 & 1.204 & \pm 0.354 & 0.834 \\
\hline & -3.054 & 1.444 & & \\
\hline \multirow[t]{2}{*}{ Thigh circumference vs. leg length } & -3.421 & 1.478 & \pm 0.188 & 0.948 \\
\hline & -3.907 & 1.560 & & \\
\hline
\end{tabular}

${ }^{1}$ All of the regression analyses are performed on pooled-sex samples.

${ }_{2}^{2}$ Most regression slopes are significantly different from zero at $P<0.01$, the rest are significant at $P<0.05$.

${ }^{3}$ In all bivariate comparisons, least-squares regression analyses are indicated on the first line, while reduced major-axis regression analyses are indicated second

cal differences between adults are due to the differential extension of common patterns of relative growth. In other words, limb and trunk proportions for Milne-Edwards's sifaka, the golden-crowned sifaka, and the western sifaka are ontogenetically scaled (much as found in the skull for these taxa [Ravosa, 1992]).

\section{Growth and size differentiation in sifakas}

At age class 6, T-tests for limb, trunk, and body weight dimensions between $P . d$. edwardsi and $P$. tattersalli are significant in all 15 cases (Table 4); that is, adult MilneEdwards's sifakas are consistently larger in size. This pattern is also demonstrated at age class 5, where 14 of 15 comparisons are significantly different, and at age class 4 , where 11 of 15 T-tests are significant. Likewise, this is indicated to a lesser extent at age class 3 , where 9 of 15 comparisons are significantly different. At age class 2 , only three significant differences are noted between sifaka postcranial measurements. Although not always statistically significant at age class $2,100 \%$ of the means for $P$. $d$. edwardsi measures exceed the means for $P$. tattersalli measures. This pattern of bodysize enlargement is maintained at later stages in ontogeny as well. While similar 
TABLE 3. Between-species ANCOVAs for both growth series and tests of positional differences for all three species

\begin{tabular}{lc}
\hline Variable $^{1}$ & Vs. body weight \\
\hline Body length & $\mathrm{NS}$ \\
Tail-crown length & $\mathrm{NS}$ \\
Tail length & $\mathrm{D}<\mathrm{T}<\mathrm{V}^{3,4}$ \\
Chest circumference & $\mathrm{NS}$ \\
Forelimb length & $\mathrm{NS}$ \\
Forefoot length & $\mathrm{NS}$ \\
Arm length & $\mathrm{NS}$ \\
Thumb length & $\mathrm{NS}$ \\
Upper arm circumference & $\mathrm{NS}$ \\
Hindlimb length & $\mathrm{T}>\mathrm{T}>\mathrm{V}^{4,5}$ \\
Hindfoot length & $\mathrm{NS}$ \\
Leg length & $\mathrm{NS}$ \\
Big-toe length & $\mathrm{NS}$ \\
Thigh circumference & $\mathrm{NS}$ \\
$\quad$ Forelimb length vs. hindlimb & \\
$\quad$ length & $\mathrm{NS}$ \\
Arm length vs. leg length & $\mathrm{NS}$ \\
Upper arm circumference vs. thigh & \\
cireumference & $\mathrm{NS}$ \\
Upper arm circumference vs. arm & \\
length & $\mathrm{NS}$ \\
\hline Thigh circumference vs. leg length & N
\end{tabular}

${ }^{1}$ No data are available for analyses of upper arm or thigh circumference in $P$. verrecuxi.

${ }^{2} \mathrm{NS}=$ no significant differences between sifaka regression lines, $P>0.05$, and no differences between the position of the adult data scatter for $P$. verreauxi with respect to the regression lines.

${ }^{3}$ Significant slope and $\mathrm{Y}$-intercept differences between sifaka leastsquares regression lines, ANCOVA $(P<0.05)$.

${ }^{4} \mathrm{D}>\mathrm{T}>\mathrm{V}$ means $P$. d edwardsi. regression line is transposed above the $P$. tattersalli line, which is in turn transposed above the adult $P$. verreauxi data scatter; $\mathrm{D}>\mathrm{T}>\mathrm{V}$ means $P$. verreauxi adult data scatter is transposed above the $P$. tattersalli regression line, which is in turn transposed above the $P$. d. edwardsi line.

${ }^{5}$ Significant Y-intercept differences between sifaka least-squares regression lines.

analyses were not possible for all measures at age class 1 , based on body weights alone, $P$. d. edwardsi (wild-caught), $P$. tattersalli (DUPC), and $P . v$. coquereli (DUPC) have fairly similarly sized neonates ranging in size from 84 to $155 \mathrm{~g}^{4}$.

At age class 6, T-tests for postcranial and body weight measures between $P$. $d$. edwardsi and $P$. verreauxi are significant in 12 of 13 cases (Table 5). Adult Milne-Edwards's

\footnotetext{
${ }^{1}$ Based on two wild-caught individuals, $P$. $d$. edwardsi has an average "neonate" weight of $145 \mathrm{~g}$. Based on 1 DUPC individual, $P$. tattersalli has a neonate weight of $98 \mathrm{~g}$. Based on 12 DUPC individuals, $P$. $v$. coquereli has an average neonate weight of 105 $\mathrm{g}$. The range for $P$. $v$. coquereli (84-129 g) includes the $P$. tattersalli value and falls just below that for $P$. d. eduardsi $\{135$ and $155 \mathrm{~g}$ ). However, whereas the data for DUPC sifakas were collected on the day of birth, the Milne-Edwards's sifaka data were collected at least several days after birth, resulting in elevated values for "neonate" weight.
}

sifakas are consistantly larger except in comparisons of tail length, where western sifakas are significantly larger, and tailcrown length, where $P$. d. edwardsi only tends to be larger (i.e., differences exist which are not statistically significant). At age class 6 , T-tests for limb, trunk, and body weight dimensions between $P$. tattersalli and $P$. verreauxi are significant in only 4 of 13 cases (Table 5 ). In this suite of analyses, golden-crowned sifakas are significantly larger in chest circumference and hindfoot length and tend to be larger in body length, forelimb length, forefoot length, arm length, hindlimb length, and big-toe length. On the other hand, western sifakas are significantly larger in tail length and tail-crown length and tend to be larger in body weight, thumb length, and leg length.

\section{Sexual dimorphism in sifakas}

Based on 15 limb, trunk, and body weight measures, adult $P$. d. edwardsi (9 females, 10 males) show significant sexual dimorphism where females are larger than males in body weight, tail-crown length, tail length, body length, and hindfoot length (Table 6). Our results also indicate that adult $P$. tattersalli (10 females, 8 males) show significant sex dimorphism in tailcrown length, body length, and forefoot length. The results further demonstrate that adult $P . v$. coquereli (5 females, 10 males) show significant sex dimorphism in body weight, leg length, hindlimb length, and forefoot length. Lastly, our results for adult $P$. $v$. verreauxi ( 4 females, 3 males) do not indicate significant sexual dimorphism in any of 13 measures. In fact, female measures do tend to be larger in 6 of 13 comparisons, whereas male measures tend to be larger in six cases (Table 6).

\section{DISCUSSION}

\section{Allometry and heterochrony in sifakas}

Propithecus diadema edwardsi, Propithecus tattersalli, Propithecus verreauxi coquereli, and Propithecus verreauxi verreauxi share common patterns of relative growth in the limbs and trunk (Table 3; Figs. 3-6), as well as in the skull and jaws (Ravosa, 1992). Our analyses suggest that $P . d$. edwardsi 


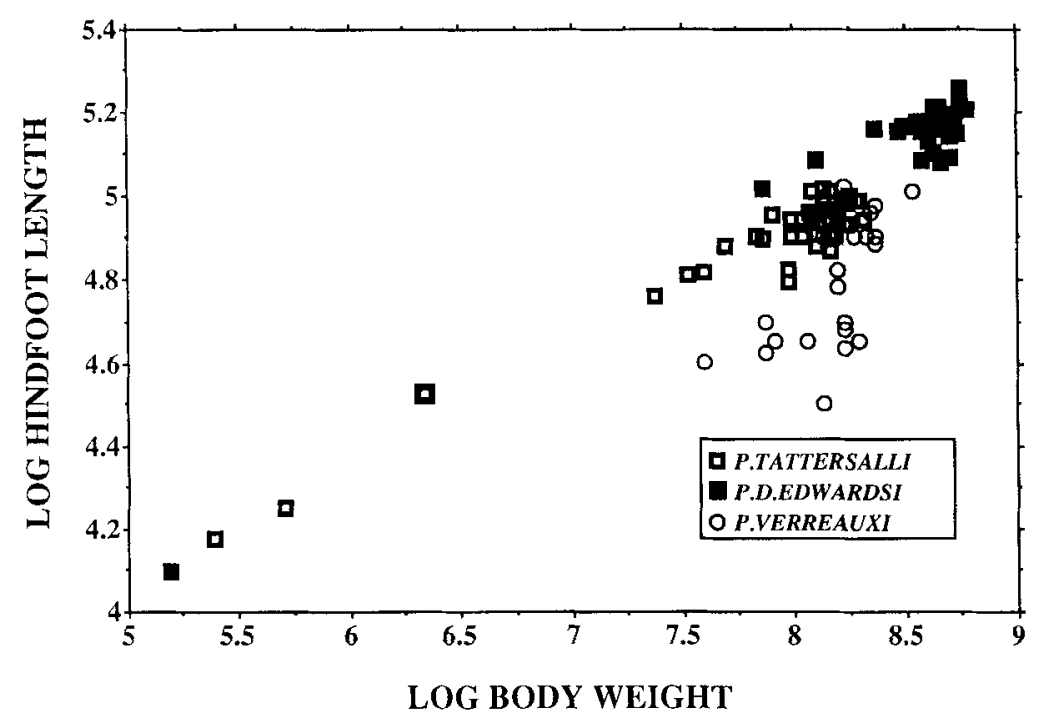

Fig. 7. A plot of $\log _{\mathrm{e}}$ hindfoot length vs. $\log _{\mathrm{e}}$ body weight. Note that the ontogenetic scaling trajectory for $P$. tattersalli does not intersect the scatter for $P$. $d$. edwardsi or $P$. verreauxi. Instead, the growth pattern for Milne-Edwards's sifaka is transposed above that for the golden-crowned sifaka and the adult data for western sifakas. These scaling differences are perhaps linked to functional differences in locomotor behavior due to interspecific variation in adult size.

attains larger adult body size mainly by growing at a faster or higher rate than $P$. tattersalli (and $P$. verreauxi) (Table 4). For instance, this is evident in the patterns of weight increases for $P . d$. edwardsi and $P$. tattersalli. At 1 year of age, juvenile $P$. $d$. edwardsi weight on average $2,950 \mathrm{~g}$, which amounts to $51 \%$ of the average adult weight of $5,837 \mathrm{~g}$. At 1 year of age, juvenile $P$. tattersalli weigh on average $2,384 \mathrm{~g}$, which amounts to $68 \%$ of the average adult weight of 3,493 g. Thus in Milne-Edwards's sifaka, whereas a lesser percentage of the adult body weight is attained by 52 weeks, this amounts to an absolutely greater increase in body weight because $P$. $d$. edwardsi weighs more and gains more weight in 1 year than the golden-crowned sifaka.

Therefore, if the smaller overall adult size and the ontogenetic trajectory of the goldencrowned sifaka (and western sifaka) more closely approximate the primitive condition for Propithecus, then the growth pattern for Milne-Edwards's sifaka follows the prediction for rate hypermorphosis because significant differences in the size of postcranial measures become more expressed in the later stages of ontogeny (Shea, 1983, 1988; Ravosa, 1992). However, if the polarity of size change were reversed, golden-crowned sifakas would be considered to have attained smaller body size via rate hypomorphosis. In fact, species differences apparently occur early in postnatal development, since by age class 2 all $P$. d. edwardsi measures at least tend to be larger than those for $P$. tattersalli (Table 4). This corresponds closely to a similar analysis of allometry and heterochrony in the sifaka cranium. That is, the majority of dimensions for all three sifakas are ontogenetically scaled and $P$. diadema develops larger adult skull size than $P$. verreauxi and $P$. tattersalli via rate hypermorphosis (Ravosa, 1992). One reason why rate hypermorphosis is perhaps more important than time hypermorphosis in the development of sifaka body-size differentiation is that data on populations of $P$. d. edwardsi, $P$. tattersilli, $P$. v. coquereli, and $P$. v. verreauxi (for $P$. v. verreauxi, see also Richard et al., 1991) indicate that sexual maturity is reached at approximately the same age of 4-5 years old (also Ravosa, 1992; Meyers and Wright, 1993). 


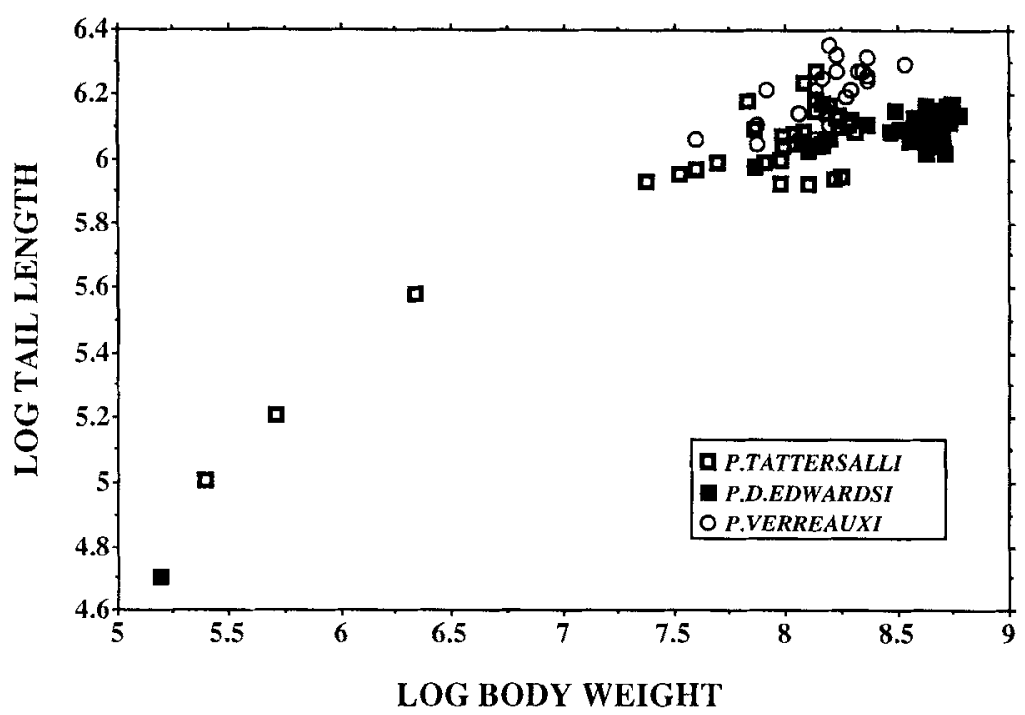

Fig. 8. A plot of $\log _{e}$ tail length vs. $\log _{e}$ body weight. Note again that the ontogenetic scaling trajectory for $P$. tattersalli does not intersect the scatter for $P$. d. edwardsi or $P$. verreauxi. Rather, the data for adult western sifakas are transposed above the scaling trajectory for the golden-crowned sifaka and that for Milne-Edwards's sifaka.

TABLE 4. Between-species T-tests at each age class

\begin{tabular}{|c|c|}
\hline Variable & $\begin{array}{c}\text { P. d. edwardsi vs. } \\
\text { P. tattersalli }{ }^{1-4}\end{array}$ \\
\hline Hindfoot length & $2,3,4,5,6$ \\
\hline Forefoot length & $2,3,4,5,6$ \\
\hline Hindlimb length & $2,3,4,5,6$ \\
\hline Body weight & $2,3,4,5,6$ \\
\hline Leg length & $2,3,4,5,6$ \\
\hline Forelimb length & $2,3,4,5,6$ \\
\hline Thumb length & $2,3,4,5,6$ \\
\hline Big-toe length & $2,3,4,5,6$ \\
\hline Thigh circumference & $2,3,4,5,6$ \\
\hline Body length & $2,3,4,5,6$ \\
\hline Upper arm circumference & $2,3,4,5,6$ \\
\hline Arm length & $2,3,4,5,6$ \\
\hline Tail-crown length & $2,3,4,5,6$ \\
\hline Chest circumference & $2,3,4,5,6$ \\
\hline Tail length & $2,3,4,5,6$ \\
\hline
\end{tabular}

${ }^{1}$ Age classes 2-6: cases where $P$ d edwardsi measures are significantly larger than $P$. tattersalli are noted in bold; otherwise, the T-tests are not significant $(P>0.05)$.

${ }^{2}$ Variables are ranked in ascending order by the age class at which species differences in bold develop.

${ }^{3}$ Not enough data spanning the entire range of age class 1 are available for T-tests at age class 1; however, based on wild-caught and DUPC data for all three species, there are no apparent differences in body weight at age class 1 (see also text).

${ }^{4} \mathrm{By}$ age class 2, though not always statistically significant, $100 \%$ of the means for $P$. d. edwardsi measures exceed the means for $P$. tattersalli measures; in fact, this pattern of body size enlargement is maintained through adulthood.

\section{Ecological bases of body size variation in sifakas}

Albrecht et al. (1990) recently described a pervasive trend in ecogeographic size varia- tion among all Malagasy lemurs or primates (see also Godfrey and Petto, 1981; Godfrey et al., 1990). They found a consistent pattern of adult size differences among sister taxa such that the largest forms were found in the central domain and progressively smaller-bodied taxa were located respectively in the east, west, north, and south. Differences in resource productivity among ecogeographic regions were suggested to be potential causes of this pattern, with the dry southern forests supposedly containing the poorest food productivity and the central plateau having the highest productivity (at least until the recent past). Sifakas provide an interesting test of models of ecogeographic variation since differences in adult size are due to ontogenetic scaling (Ravosa, 1992) and different taxa inhabit several ecogeographic regions: $P$. diadema is located in the moist eastern rainforests, $P$. verreauxi is found in the dry northwest and semi-arid southwest, and $P$. tattersalli is located in the dry northeast. In this section we address how ecological factors may influence patterns of body-size differentiation among sifakas and other Malagasy lemurs. In particular, two alternative models regarding bodysize variation are considered: adult body 
TABLE 5. Between-species T-tests at adulthood

\begin{tabular}{|c|c|c|c|}
\hline Variable $^{1,2}$ & $\begin{array}{l}\text { P. d. edwardsi vs. } \\
\text { P. tattersalli }\end{array}$ & $\begin{array}{l}P . d . \text { edwardsi vs. } \\
P . \text { verreauxi }\end{array}$ & $\begin{array}{l}\text { P. tattersalli vs. } \\
P . \text { verreauxi } i^{5}\end{array}$ \\
\hline Body weight & $\mathrm{D}>\mathrm{T}$ & $\mathrm{D}>\mathrm{V}$ & $\mathrm{T}<\mathrm{V}$ \\
\hline Body length & $\mathbf{D}>\mathbf{T}$ & $\bar{D}>V$ & $\mathrm{~T}>\mathrm{V}$ \\
\hline Tail-crown length & $\mathrm{D}>\mathrm{T}$ & $\mathrm{D}>\mathrm{V}$ & $\mathbf{T}<\mathbf{V}$ \\
\hline Tail length & $\mathbf{D}>\mathbf{T}$ & $\mathrm{D}<\mathrm{V}$ & $\mathrm{T}<\mathrm{V}$ \\
\hline Chest circumference & $\mathrm{D}>\mathrm{T}$ & $\mathrm{D}>\mathrm{V}$ & $T>V$ \\
\hline Forelimb length & $\mathrm{D}>\mathrm{T}$ & $\bar{D}>\mathrm{V}$ & $\mathrm{T}>\mathrm{V}$ \\
\hline Forefoot length & $\mathrm{D}>\mathrm{T}$ & $\mathrm{D}>\mathrm{V}$ & $\mathrm{T}>\mathrm{V}$ \\
\hline Arm length & $\bar{D}>\mathbf{T}$ & $\mathbf{D}>\mathrm{V}$ & $\mathrm{T}>\mathrm{V}$ \\
\hline Thumb length & $\mathrm{D}>\mathrm{T}$ & $\mathrm{D}>\mathrm{V}$ & $\mathrm{T}<\mathrm{V}$ \\
\hline Upper arm circumference & $\mathrm{D}>\mathrm{T}$ & NA & NA \\
\hline Hindlimb length & $\mathrm{D}>\mathrm{T}$ & $\mathrm{D}>\mathrm{V}$ & $\mathrm{T}>\mathrm{V}$ \\
\hline Hindfoot length & $\mathrm{D}>\mathrm{T}$ & $\mathrm{D}>\mathrm{V}$ & $\mathrm{T}>\mathrm{V}$ \\
\hline Leg length & $\mathrm{D}>\mathrm{T}$ & $\mathrm{D}>\mathrm{V}$ & $\mathrm{T}<\mathrm{V}$ \\
\hline Big-toe length & $\mathbf{D}>\mathbf{T}$ & D $>$ V & $\mathrm{T}>\mathrm{V}$ \\
\hline Thigh circumference & $\mathrm{D}>\mathrm{T}$ & NA & $\mathrm{NA}$ \\
\hline
\end{tabular}

${ }^{1}$ Cases where adult measures are significantly different are noted in bold; otherwise, the T-tests are not significant $(P>0.05)$; in most cases where significant differences are indicated, $P<0.01$.

${ }^{2}$ NA means not applicable, since there are no data on upper arm or thigh circumference for $P$. verreauxi.

${ }^{3} \mathrm{D}>$ T means $P$. d. edwardsi measure is larger than that for $P$. tattersalli.

${ }^{4} \mathrm{D}>\mathrm{V}$ means $P$. d. edwardsi measure is larger than that for $P$. verreauxi, whereas $\mathrm{D}<\mathrm{V}$ means $P$. verreauxi measure is larger than that for $P$. $d$. edwardsi.

${ }_{5} \mathrm{~T}>\mathrm{V}$ means $P$. tattersalli measure is larger than that for $P$. verreauxi, whereas $\mathrm{T}<\mathrm{V}$ means $P$. verreauxi measure is larger than that for $P$. tattersalli.

TABLE 6. Between-sex T-tests at adulthood

\begin{tabular}{|c|c|c|c|c|}
\hline Variable $^{1-3}$ & P. d. edwardsi & P. tattersalli & P. v. coquereli & P. v. verreauxi \\
\hline Body weight & $\mathbf{F}>\mathbf{M}$ & $\mathrm{F}>\mathrm{M}$ & $\mathbf{F}>\mathbf{M}$ & $\mathrm{F}<\mathrm{M}$ \\
\hline Body length & $\mathbf{F}>\mathbf{M}$ & $\mathbf{F}>\mathbf{M}$ & $\mathrm{F}>\mathrm{M}$ & $\mathrm{F}<\mathrm{M}$ \\
\hline Tail-crown length & $\mathbf{F}>\mathbf{M}$ & $\mathrm{F}>\mathrm{M}$ & $\mathrm{F}>\mathrm{M}$ & $\mathrm{F}=\mathrm{M}$ \\
\hline Tail length & $\mathbf{F}>\mathbf{M}$ & $\mathrm{F}>\mathrm{M}$ & $\mathbf{F}>\mathbf{M}$ & $\mathrm{F}>\mathrm{M}$ \\
\hline Chest circumference & $\mathrm{F}>\mathrm{M}$ & $\mathrm{F}>\mathrm{M}$ & $\mathrm{F}>\mathrm{M}$ & $\mathrm{F}<\mathrm{M}$ \\
\hline Forelimb length & $\mathrm{F}>\mathrm{M}$ & $\mathrm{F}>\mathrm{M}$ & $\mathrm{F}>\mathrm{M}$ & $\mathrm{F}>\mathrm{M}$ \\
\hline Forefoot length & $F>M$ & $\mathbf{F}>\mathbf{M}$ & $F>M$ & $F>M$ \\
\hline Arm length & $\mathrm{F}>\mathrm{M}$ & $\mathrm{F}>\mathrm{M}$ & $\mathrm{F}>\mathrm{M}$ & $\mathrm{F}>\mathrm{M}$ \\
\hline Thumb length & $\mathrm{F}>\mathrm{M}$ & $\mathrm{F}>\mathrm{M}$ & $\mathrm{F}>\mathrm{M}$ & $\mathrm{F}<\mathrm{M}$ \\
\hline Upper arm circumference & $\mathrm{F}>\mathrm{M}$ & $\mathrm{F}>\mathrm{M}$ & $\mathrm{NA}$ & $\mathrm{NA}$ \\
\hline Hindlimb length & $\mathrm{F}>\mathrm{M}$ & $\mathrm{F}>\mathrm{M}$ & $\mathrm{F}>\mathrm{M}$ & $\mathrm{F}>\mathrm{M}$ \\
\hline Hindfoot length & $\mathbf{F}>\mathbf{M}$ & $\mathbf{F}>\mathbf{M}$ & $F>M$ & $F>M$ \\
\hline Leg length & $\mathrm{F}>\mathrm{M}$ & $\mathrm{F}>\mathrm{M}$ & $\mathbf{F}>\mathbf{M}$ & $\mathrm{F}<\mathrm{M}$ \\
\hline Big-toe length & $\mathrm{F}>\mathrm{M}$ & $\mathrm{F}>\mathrm{M}$ & $\mathrm{F}>\mathrm{M}$ & $\mathrm{F}<\mathrm{M}$ \\
\hline Thigh circumference & $F>M$ & $\mathrm{~F}>\mathrm{M}$ & NA & NA \\
\hline
\end{tabular}

${ }^{1}$ Cases where adult measures are significantly different are noted in bold; otherwise, the T-tests are not significant $(P>0.05)$; in most cases where significant differences are indicated, $P<0.01$.

${ }^{2}$ NA means not applicable, since there are no data on upper arm or thigh circumference for $P$, verreauxi.

${ }^{3} \mathbf{F}>\mathrm{M}$ means female measure is larger than that for males, $\mathrm{F}<\mathrm{M}$ means male measure is larger than that for females, and $\mathrm{F}=\mathrm{M}$ means female measure equals male measure.

size is set by habitat or forage quality, and adult body size if set by dry-season constraints on food quality and distribution. Ultimately, we show that it is necessary to examine ontogeny so as to better understand the effects of these two selective factors on patterns of size variation in sifakas.

The first model is based upon a well-documented relationship between body size and forage quality in mammalian herbivores. Larger species tend to ingest greater percentages of lower-quality forage (e.g., Janis,
1976; Demment and van Soest, 1985; Sailer et al., 1985; McNaughton and Georgiadia, 1986). This correlation is due to the energetic and digestive benefits of larger body size. Specifically, larger mammals have longer gut passage time due to an absolutely larger digestive tract which allows for greater absorption of nutrients from an otherwise lower-quality diet (Janis, 1976; Chivers and Hladik, 1984; Demment and van Soest, 1985; Sailer et al., 1985; McNaughton and Georgiadis, 1986), energetically more 
efficient locomotion (Schmidt-Nielsen, 1972, 1984), and lower metabolic demands (Kleiber, 1961; Schmidt-Nielsen, 1984). This model predicts that among recently diverged sister taxa, larger-bodied forms should be associated with poorer-quality habitats.

The second model is based on a study of several primate communities (Terborgh and van Schaik, 1987), most important of which is information from New World monkeys (Terborgh, 1983). Terborgh and van Schaik suggest that resource seasonality places energetic constraints on adult body size. In particular, they note that in seasonal habitats the dry season can be a critical period characterized by relatively smaller patch size and lower patch quality which can lead to strong selective pressures for smaller adult body size. Thus, smaller-bodied forms should be associated with more seasonal environments.

To test the first model of ecogeographic size variation in sifakas we examined a general measure of folivore habitat quality. This habitat quality index, which is the ratio of protein to fiber in samples of mature leaves from trees in a given forest, has been a useful predictor of folivorous anthropoid biomass (Waterman et al., 1988; Oates et al., 1990) and has been tested recently for Malagasy forests (Ganzhorn, 1992). Folivorous primate biomass in Madagascar shows a positive relationship with the protein-tofiber ratio of mature leaves and most Malagasy folivores select for high ratio foods (Ganzhorn, 1992). Western forests have higher protein-to-fiber ratios than eastern forests and a correspondingly higher primate folivore biomass (Ganzhorn, 1992). Consequently, the western Malagasy forests have a higher-quality habitat for folivores such as sifakas (contra Albrecht et al., 1990). Oddly enough, as the eastern rainforest has a lower carrying capacity for lemurs, rainfall is negatively correlated with lemur folivore biomass (Ganzhorn, 1992). Moreover, as predicted by the first model, the largest sifakas are located in the poorerquality eastern rainforest (Table 5).

On the other hand, similar support exists for the effects of resource seasonality as a limit on adult body size in sifakas (Terborgh and van Schaik, 1987). Seasonality in Madagascar can be described roughly as a "dry" season with low availability of high-protein immature leaves and insects (although possibly a high abundance of some fruits [Overdorff, 1991]) and a "wet" season with high availability of immature leaves and insects (Hladik, 1980; Hladik et al., 1980; Meyers and Wright, 1993). In contrast to the eastern region of Madagascar, the western, northern, and southern regions have greater seasonal scarcity of rainfall (Griffiths and Ranaivoson, 1972) and presumably a concomitant reduction in food resources. A comparative study of resource tracking (Meyers and Wright, 1993) shows that the eastern rainforest of $P$. d. edwardsi has a more even distribution of food over the course of a year than does the northeastern dry forest of $P$. tattersalli (and western $P$. verreauxi by inference [see Richard, 1978]). In this case the west, north, and south have the most variable resources, fluctuating from very good in the wet season (note the leaf quality index [Ganzhorn, 1992]) to very poor in the dry season. As progressively smaller-bodied adult sifakas are located in the east, northwest, northeast, and southwest (see also Albrecht et al., 1990), this supports the second model suggesting that adult body size is set by dry-season constraints on food quality and distribution.

The two models defined earlier have more general implications regarding ecogeographic size variation in Malagasy lemurs. If we consider that all primates derive the majority of protein from either leaves or insects (Hladik et al., 1980; Kay, 1984; Richard, 1985) and that may herbivorous insects are subject to the same plant defensive strategies as mammals (e.g., fiber digestibility, secondary defensive compounds [Coley, 1982), one possible explanation for the common pattern of ecogeographic size variation in Malagasy lemurs is that leaf quality directly influences the gross availability of protein to primary and in turn secondary consumers. Therefore, the factors associated with each model presumably affect all Malagasy primates more or less irrespective of dietary preference.

As both models predict the observed patterns of adult body-size variation in sifakas, 
it is not possible to distinguish between either model. It is of further interest to note that both scenarios, with overall adult size as the target of selection, are consistent with a pervasive pattern of ontogenetic scaling in sifaka postcranial and cranial (Ravosa, 1992) morphology. That is, since sifakas share similar patterns of relative growth, it is most parsimonious to assume that selection for rapid body-size changes has occurred with little alteration of specific body proportions apart from those expected due to ontogenetic scaling (cf. Gould, 1975, 1977; Shea, 1988).

So far, the discussion has centered on two models concerning the ecological basis of adult body-size variation in sifakas. Essentially, both models are supported. In this regard, it is important to stress that ontogenetic data provide a unique perspective with which to further address this problem. For example, the depth of the seasonal tough in food availability is a major determinant of juvenile starvation or mortality risk (cf. Janson and van Schaik, 1992). Moreover, when combined with ecological data, information on ontogeny may provide insight into the direction or polarity of size change among sifakas. If the first model regarding forage quality and body size is to be supported, P. $d$. edwardsi should grow slower, on average, due to the poorer-quality habitat of eastern Madagascar. On the other hand, if the second model regarding resource seasonality and body size is to be supported, $P$. verreauxi would be expected to grow at an overall slower rate because of smaller patch size and lower patch quality in the dry season. Likewise, $P$. $d$. edwardsi might grow faster, on average, due to the dampened resource oscillations of the eastern rainforest. As stated above, neither forage quality nor habitat quality remains static in Madagascar (Ganzhorn, 1992; Meyers and Wright, 1993).

Our results suggest that eastern $P$. d. edwardsi grow at a faster annual rate than $P$. tattersalli (Table 4) and P. verreauxi (Ravosa, 1992), thus supporting predictions of the second model. However, we stress that truly differentiating between these two alternative models is possible only with comparative growth data collected at a finer time scale than presently available for sifakas.

Such data are available for ringtailed lemurs (Lemur catta). Recent work by Pereira (1993) demonstrates the presence of innate seasonal reductions in juvenile $L$. catta growth rate corresponding to the dry season of the southern forest. This seasonal reduction in growth rate illustrates one strategy to reduce juvenile mortality risk for lemurs inhabiting highly seasonal environments. These results also support the importance of seasonal reduction in resouce availability as a determinant of growth rate. Moreover, smaller adult body size could be a correlate of such reduced seasonal growth rates if the period of growth from birth to adulthood is similar among sister taxa (due to constraints on the duration of ontogeny). This perhaps characterizes sifakas, as heterochronic changes occur primarily with respect to alterations in growth rate as the means of body-size differentiation (Table 4).

In any event, it is fruitful to speculate about what would be expected if more detailed ontogenetic data were available for sifakas. For the first model to be supported, $P$. d. edwardsi should grow at a slower yearly rate than $P$. tattersalli and $P$. verreauxi due to the presence of lower-quality forage in the eastern rainforest. Such differences are not observed for sifakas, however. For the second model to be supported, peak growth rates should be higher in the higherquality western deciduous forests of Madagascar during the wet season, while growth rates for eastern sifakas should be relatively higher in the dry season due to the lower monthly variance in food availability. In this scenario, it is possible that eastern lemurs might attain a higher annual growth rate than their sister taxa despite a lower peak growth rate (during the wet season), if growth rates are significantly higher in the dry season. This may explain the observed pattern of faster yearly growth rates in $P$. $d$. edwardsi vs. those for $P$. tattersalli and $P$. verreauxi (Table 4).

In sum, we posit that ecogeographic size variation in Malagasy lemurs results from a balance of two factors: average habitat or forage quality, and resource seasonality. Thus, although it is not directly possible to 
discern the relative importance of either model of ecogeographic size variation, $P . d$. edwardsi does apparently benefit from larger body size due to the dietary disadvantages of the eastern rainforest. However, it is equally likely that the smaller body sizes of $P$. tattersalli, $P$. v. coquereli, and $P$. v. verreauxi are due to dry-season constraints on food quality and patch size. In fact, this latter interpretation may be more likely because the ontogenetic data support the importance of seasonal variation in resource availability as a constraint on growth rate. Broadly speaking, adult body weight among Malagasy primates should be inversely related to forage quality and the degree of seasonal fluctuations in food resources. Further examination of these factors will depend on the availability of detailed growth data and detailed ecological studies for other lemur groups. Moreover, such information will help explain ecogeographic size variation not only in Malagasy folivores but also among those primates which derive protein from insects.

\section{Functional implications of scaling patterns in sifakas}

One of only two cases where sifaka limb proportions are not ontogenetically scaled is noted for hindfoot length vs. body weight. In this comparison the regression line for hindfoot length in Milne-Edwards's sifaka is transposed above that for the goldencrowned sifaka and the adult scatter for western sifakas in turn (Table 3; Fig. 7). While little behavioral data exists to adequately address the implications of this scaling pattern, perhaps these differences are related to variation in the diameter of vertical supports typically utilized by the different species (Demes, personal communication), with relatively larger hindfeet being positively correlated with larger vertical supports.

The other difference among sifaka scaling patterns is noted for tail length vs. body weight, with the adult scatter for tail length in western sifakas transposed above the regression line for the golden-crowned sifaka and that for Milne-Edwards's sifaka in turn (Table 3; Fig. 8). Although little is known about the significance of tail morphology on leaping performance (Demes et al., 1991), it is noteworthy that there is a trend for smaller-bodied sifakas to have relatively longer tails. The fact that Indri, the largest living indriid, has a very diminutive tail, and $A v a h i$, the smallest living indriid, has the relatively longest tail (Demes, 1991), indicates an interesting trend in tail proportions among all indriids.

The sifaka ontogenetic scaling patterns also have interesting implications for the evolutionary development of a low intermembral index or IMI (i.e., arm length/leg length $\times 100)$ in $P . d$. edwardsi (IMI $=67)$, $P$. tattersalli (IMI $=65$ ), and $P$. verreauxi (IMI $=60$ ). Among arboreal primates like sifakas, a very low adult IMI is generally considered a locomotor adaptation for propulsive hindlimb-dominated leaping (e.g., Jungers, 1978, 1985). Because this means that in adult sifakas the legs are considerably longer than the arms, it might be assumed that this pattern results from strong positive allometry of hindlimb growth. In both growth series, however, most scaling coefficients for sifaka arm and leg dimensions indicate slight negative allometry to slight positive allometry. Thus, the combination of slight allometry of limb growth and low adult IMIs suggests that sifaka limb proportions are determined prenatally in large part, rather than being achieved via higher postnatal growth rates in the hindlimb or lower postnatal growth rates in the forelimb. That is, IMIs for a given species appear to be present at birth and maintained with only minor changes during growth. In fact, similar patterns have been demonstrated for the African apes (Shea, 1981), the Asian apes (Jungers and Hartman, 1988; Jungers and Cole, 1992), and callitrichid monkeys (Falsetti and Cole, 1992); therefore, perhaps this is a common phenomenon for mammals.

A comparison of sifaka IMIs provides some evidence in favor of the allometric argument that, on average, larger-bodied arboreal taxa require relatively longer forelimbs (i.e., higher IMIs) to maintain climbing and clinging abilities on vertical supports (Cartmill, 1974, 19855; Jungers, 1978, 19855). For instance, Shea (1981) 
found that among the African apes, largerbodied adult gorillas have the highest IMIs, followed next by the smaller-sized common chimpanzees and then in turn by the yet smaller-bodied bonobos. Among sifakas, comparisons between the larger-bodied $P . d$. edwardsi and smaller-bodied $P$. verreauxi provide support for the allometric model regarding IMIs. There is also a similarly interesting subspecific pattern in IMIs whereby the larger-bodied $P . v$. coquereli $(\mathrm{IMI}=62$ ) has a higher value than the smaller-bodied $P$. $v$. verreauxi $(\mathrm{IMI}=58)$. On the other hand, data for $P$. tattersalli provide less support for this model. While closer in body size to western sifakas, the golden-crowned sifaka has an IMI very close in value to that for Milne-Edwards's sifaka. Perhaps this highlights certain postural or locomotor specializations of the appendicular skeleton in P. tattersalli.

One difference between sifakas and the African apes is that sifaka IMIs decrease slightly during growth. For instance, $P$. tattersalli has an IMI of 67 at 3 weeks old, which decreases slightly to an IMI of 65 at adulthood. On the other hand, $P$. d. edwardsi has an IMI of 71 at 1 week old, which decreases to an IMI of 67 at adulthood. Therefore, the interspecific pattern across sifakas, where larger individuals have higher IMIs, differs from the ontogenetic pattern within each species, where larger individuals tend to have lower IMIs. Perhaps the presence of higher IMIs (i.e., longer neonate forelimbs) early in ontogeny among taxa like sifakas facilitates better grasping abilities. This may be beneficial for a small animal required to cling to its mother during frequent and forceful leaping bouts.

\section{Sexual dimorphism in sifakas}

Our study is also relevant to recent work on the importance of female dominance and the development of sexual dimorphism in sifakas (i.e., Kappeler, 1990, 1991; Jenkins and Albrecht, 1991; Richard et al., 1991; Ravosa, 1992; Richard, 1992; Godfrey et al., 1993). Based on limb, trunk, and body weight measures, adult $P$.d.edwardsi show significant sexual dimorphism where females are significantly larger than males in one-third of all dimensions (Table 6). This corresponds with Ravosa's (1992) study in which he found significant sexual dimorphism in 16 of 22 skull dimensions for 15 adult $P$. diadema ( 8 females, 7 males). Kappeler's (1990) analysis likewise indicates significant body weight dimorphism in diademed sifakas, although non-significant differences are indicated in his more recent investigation (Kappeler, 1991). Our analyses also indicate that adult $P$. tattersalli show significant sex dimorphism in only about one-fifth of all measurements. Adult $P . v$. coquereli show significant sex dimorphism in about one-third of all measures. For example, adult male weight averages $3,704 \mathrm{~g}$, whereas that for adult females is $4,280 \mathrm{~g}$. On the other hand, our sample of adult $P . v$. verreauxi shows a lack of significant sexual dimorphism in any dimensions. In fact, in about half of the comparisons for P. v. verreauxi, adult male measures (e.g., body weight $3,251 \mathrm{~g}$ ) tend to be larger than those for adult females $(2,946 \mathrm{~g})$. Therefore, depending on the subspecies and, to a lesser extent, perhaps the sample size, $P$. verreauxi may or may not be monomorphic as suggested by various workers (Kappeler, 1990, 1991; Jenkins and Albrecht, 1991; Richard et al., 1991; Ravosa, 1992; Richard, 1992; Godfrey et al., 1993). However, analyses of all three species of Propithecus demonstrate a consistent trend of sexual dimorphism which is interesting biologically even if not always significant statistically. Moreover, the pattern of sexual dimorphism across sifakas is allometric, with larger species and subspecies exhibiting a greater degree of sexual size differentiation (sensu Rensch, 1959). This is the only documented case of this phenomenon among Malagasy primates.

It is important to note that while some sifaka body dimensions display significant sexual dimorphism, the degree of dimorphism is slight in the absolute sense, especially as compared to similarly sized anthropoid primates. In most comparisons, adult female sifakas simply tend to be larger than adult males. Variation in sexual size differentiation, as noted earlier, may result from developmental differences in access to higher-quality foods since sifakas exhibit female dominance (Jolly, 1984; Richard and 
Nicoll, 1987; Kappeler, 1990, 1991; Godfrey et al., 1993). While not examined directly, the fact that the majority of sifaka allometric comparisons are coincidental does suggest that growth trajectories for males and females are likely to be ontogenetically scaled, much as suggested by similar analyses of sifaka cranial dimensions (Ravosa, 1992). Moreover, with the limited data available on sexual patterns of weight increases for $P$. d. edwardsi and $P$. tattersalli, it appears that sexual differentiation occurs early in ontogeny. At one year of age, male and female $P$. $d$. edwardsi weigh, on average, 2,600 $\mathrm{g}$ and $3,300 \mathrm{~g}$, respectively; this amounts to $46 \%$ of the adult male weight $(5,640 \mathrm{~g})$ and $55 \%$ of the adult female weight $(6,033 \mathrm{~g})$. At 1 year of age, male and female $P$. tattersalli weigh, on average, $2,017 \mathrm{~g}$ and $2,750 \mathrm{~g}$ respectively; this amounts to $59 \%$ of the adult male weight $(3,394 \mathrm{~g})$ and $77 \%$ of the adult female weight $(3,592 \mathrm{~g})$. Therefore, our analyses tentatively indicate an interesting pattern whereby females of both taxa gain a greater percentage of adult body weight in the first year than do males. This phenomenon is related perhaps to the presence of female dominance in sifakas and therefore may characterize other such lemurs as well.

\section{CONCLUSIONS}

Most differences in body proportions among Milne-Edwards's sifaka, the goldencrowned sifaka, Coquerel's sifaka, and Verreaux's sifaka result from the differential extension of common patterns of relative growth or ontogenetic scaling via the heterochronic process of rate hypermorphosis (Ravosa, 1992). Our analyses suggest that Propithecus diadema edwardsi has evolved larger body size to better cope with the lower-quality forage of the eastern rainforest habitat, which differs from the higherquality forage of the dry-forest environment of Propithecus tattersalli and Propithecus verreauxi coquereli and the semi-arid climate of Propithecus verreauxi verreauxi. In addition, our analyses suggest that $P$. tattersalli, $P$. v. coquereli, and $P$. v. verreauxi have evolved smaller adult body sizes due to greater seasonal variation in resource availability of their respective regions in Mada- gascar. The fact that sifaka body-size differentiation occurs primarily via differences in growth rate is also due apparently to differences in resource seasonality (and thus juvenile mortality risk) between the moist eastern rainforest and the more temperate northeast and west.

The allometric analyses considered here further impact upon previous interspecific studies of postcranial morphology in Malagasy primates by specifically demonstrating the utility of an ontogenetic criterion of subtraction regarding locomotor form and function. For instance, sifaka scaling comparisons highlight differences in patterns of relative growth for the hindfoot and tail which may be related to differences in positional behavior and locomotor requirements. Moreover, comparisons across species further support the arguments of Jungers (1978, 1985) and Cartmill (1974, 1985 ) regarding size-required changes in intermembral indices. On the other hand, within-species analyses indicate a lack of correspondence between ontogenetic and interspecific differences in limb scaling due perhaps to differing functional constraints on limb growth and form.

In another suite of analyses, $P . d . e d-$ wardsi exhibits significant sexual dimorphism in one-third of all adult comparisons, whereas $P$. tattersalli exhibits significant sexual dimorphism in one-fifth of all adult comparisons. Among western sifakas, $P$. $v$. coquereli exhibits significant sex dimorphism in about one-third of all adult comparisons, whereas adult $P$. v. verreauxi show no significant differences between the sexes, much as demonstrated in earlier studies. All three species, however, show a trend toward sexual dimorphism in all adult variables which is unique among Malagasy primates. Moreover, this trend is apparently more marked with increased body size, such that in larger-bodied taxa, body size differences between adult females and adult males are absolutely greater.

Our study has attempted to integrate data on body growth and scaling, behavioral ecology, and life-history variation so as to better characterize the developmental bases of ecogeographic and sexual size patterns in sifakas. Unfortunately, however, such data 
are typically rare. In this regard, additional long-term comparative analyses would clearly benefit our understanding of the effects of phyletic size change on locomotor behavior and morphological evolution in other groups of closely related primates (cf. Hurov, 1991; Doran, 1992; Shea, 1992).

\section{ACKNOWLEDGMENTS}

We thank the government of the Democratic Republic of Madagascar, specifically the Ministry of Higher Education (MINESUP), the Ministry of Animal Production and Water and Forests (MPAEF), and the Direction of Water and Forests (DEF, SPEF-Antsiranana) for permission to collect morphometric data on sifakas. Financial support for this research was provided by the National Institutes of Health (DE05595) to M.J.R., the National Science Foundation (INT-8602286) to K.E.G., the National Geographic Society (3980-88) to K.E.G., the Duke University Research Council to K.E.G., the Douracouli Foundation to D.M.M., the World Wildlife Fund (US-4523) to D.M.M., Mr. and Mrs. R. Meyers, and the Department of Biological Anthropology and Anatomy, Duke University. Drs. B. Demes, J. Ganzhorn, L. Godfrey, A. Richard, C. van Schaik, and B. Shea and an anonymous reviewer are thanked for many helpful comments and discussion. The aid of Ms. E. Fox, Ms. R. Absher, Mr. J. Drake, Mr. Bienvenue, Mr. Blaid Manantsoa, and Dr. D. Garrell is also greatly appreciated. This is Duke University Primate Center publication 531.

\section{LITERATURE CITED}

Albrecht GH, Jenkins PD, and Godfrey LR (1990) Ecogeographic size variation among the living and subfossil prosimiams of Madagascar. Am. J. Primatol. 22:1-50.

Buschang PH (1982) The relative growth of the limb bones for Homo sapiens-as compared to anthropoid apes. Primates 23:465-468.

Cartmill M (1974) Pads and claws in arboreal locomotion. In FA Jenkins (ed.): Primate Locomotion. New York: Academic Press, pp. 45-83.

Cartmill M (1985) Climbing. In M Hildebrand, DM Bramble, KF Liem, and DB Wake (eds.): Functional Vertebrate Morphology. Cambridge: Harvard University Press, pp. 73-88.

Chivers DJ, and Hladik CM (1984) Diet and gut morphology in primates. In DJ Chivers, BA Wood, and A
Bilsborough (eds.): Food Acquisition and Processing in Primates, New York: Plenum Press, pp. 213-230.

Cock AG (1966) Genetical aspects of form and growth in animals. Q. Rev. Biol. 41:131-190.

Coley PD (1982) Rates of herbivory on different tropical trees. In EG Leigh, AS Rand, and DM Windsor (eds.): The Ecology of a Tropical Forest. Washington, DC: Smithsonian Institution Press, pp. 123-132.

Demes B (1991) Biomechanische Allometrie: Wie die Korpergrosse Fortbewegung und Korperform von Primaten bestimmt. Cour. Forsch.-Inst. Senck. 141: $1-83$.

Demes B, Forchap E, and Herwig H (1991) They seem to glide: Are there aerodynamic effects in leaping prosimian primates? Z. Morphol, Anthropol. 78:373-385.

Demment MW, and van Soest PJ (1985) A nutritional explanation for body-size patterns of ruminant and non-ruminant herbivores. Am Nat. 125:641-647.

Doran DM (1992) The ontogeny of chimpanzee and pygmy chimpanzee locomotor behavior: A case study of morphological paedomorphism and its behavioral correlates. J. Hum. Evol. 23:139-157.

Falsetti AB, and Cole TM (1992) Relative growth of the postcranial skeleton in callitrichids. J. Hum. Evol. 23:79-92.

Ganzhorn JU (1992) Leaf chemistry and the biomass of folivorous primates in tropical forests: Test of a hypothesis. Oecol. 91:540-547.

Glander KE, Fedigan LM, Fedigan L, and Chapman C (1991) Field methods for capture and measurement of three monkey species in Costa Rica. Folia Primatol. $57: 70-82$.

Glander KE, and Simons EL (in preparation) Morphometrics of Propithecus verreauxi.

Glander KE, Wright PC, Daniels PS, and Merenlender AM (1992) Morphometrics and testicle size of rain forest lemur species from southeastern Madagascar. J. Hum. Evol. 22:1-17.

Godfrey LR, Lyon SK, and Sutherland MR (1993) Sexual dimorphism in large-bodied primates: The case of the subfossil lemurs. Am. J. Phys. Anthropol. 90:315-334.

Godfrey LR, and Petto AJ (1981) Clinal size variation in Archaeolemur spp. on Madagascar. In AB Chiarelli and RS Corruccini (eds.): Primate Evolutionary Biology. Berlin: Springer-Verlag, pp. 14-34.

Godfrey LR, Sutherland MR, Petto AJ, and Boy DS (1990) Size, space and adaptation in some subfossil lemurs from Madagascar. Am. J. Phys. Anthropol. 81: 45-66.

Gomez AM (1992) Primitive and derived patterns of relative growth among species of Lorisidae. J. Hum. Evol. 23:219-233.

Gomez AM (in press) Ontogenetic scaling of the limbs and trunk of the Asian Lorisidae: Nycticebus coucang, Nycticebus pygmaeus, and Loris tardigradus. Am. J. Phys. Anthropol.

Gould SJ (1975) Allometry in primates, with emphasis on scaling and the evolution of the brain. In FS Szalay (ed.): Approaches to Primate Paleobiology. Contributions to Primatology, Vol. 5. Basel: S Karger, pp. 244 292.

Gould SJ (1977) Ontogeny and Phylogeny. Cambridge: Harvard University Press. 
Griffiths JF, and Ranaivoson R (1972) Madagascar. In JF Griffiths (ed.): World Survey of Climatology, Vol. 10. The Hague: W. Junk, pp. 87-144.

Hladik A (1980) The dry forest of the west coast of Madagascar: Climate, phenology, and food available for prosimians. In P Charles-Dominique, HM Cooper, A Hladik, CM Hladik, E Pages, GF Pariente, A PetterRousseaux, JJ Petter, and A Schilling (eds.): Nocturnal Malagasy Primates. Ecology, Physiology, and Behavior. New York: Academic Press, pp. 3-40.

Hladik CM, Charles-Dominique P, and Petter JJ (1980) Feeding strategies of five nocturnal prosimians in the dry forest of the west coast of Madagascar. In P. Charles-Dominique, HM Cooper, A Hladik, CM Hladik, E Pages, GF Pariente, A Petter-Rousseaux, JJ Petter, and A Schilling (eds.): Nocturnal Malagasy Primates, Ecology, Physiology, and Behavior. New York: Academic Press, pp. 41-73.

Hurov JR (1991) Rethinking primate locomotion: What can we learn from development? J. Motor Behav. 23:211-218.

Janis C (1976) The evolutionary strategy of the Equidae and the origins of rumen and caecal digestion. Evolution 30:757-774.

Janson CH, and van Schaik CP (1992) Ecological risk aversion in juvenile primates: Slow and steady wins the race. In ME Pereira and LA Fairbanks (eds.): Juvenile Primates: Life History, Development and Behavior. New York: Oxford University Press.

Jenkins PD, and Albrecht GH (1991) Sexual dimorphism and sex ratios in Madagascan prosimians. Am. J. Primatol. 24:1-14.

Jolly A (1984) The puzzle of female feeding priority. In MF Small (ed.): Female Primates: Studies by Women Primatologists. New York: A.R. Liss, pp. 197-215.

Jungers WL (1978) The functional significance of skeletal allometry in Megaladapis in comparison to living prosimians. Am. J. Phys. Anthropol. 19:303-314.

Jungers WL (1985) Body size and scaling of limb proportions in primates. In WL Jungers (ed.): Size and Scaling in Primate Biology. New York: Plenum Press, pp. 345-382.

Jungers WL, and Cole MS (1992) Relative growth and shape of the locomotor skeleton in lesser apes. $J$. Hum. Evol. 23:93-105.

Jungers WL, Cole TM, and Owsley DW (1988) Multivariate analysis of relative growth in the limb bones of Arikara Indians. Growth Dev. Aging 52:103-107.

Jungers WL, and Fleagle JG (1980) Postnatal growth allometry of the extremities in Cebus albifrons and Cebus apella: A longitudinal and comparative study. Am. J. Phys. Anthropol. 53:471-478.

Jungers WL, and Hartman SE (1988) Relative growth of the locomotor skeleton in orang-utans and other largebodied hominoids. In JH Schwartz (ed.): Orang-utan Biology. Oxford: Oxford University Press, pp. 347-359.

Jungers WL, and Susman RL (1984) Body size and skeletal allometry in African apes. In RL Susman (ed.): The Pygmy Chimpanzee: Evolutionary Biology and Behavior. New York: Plenum Press, pp. 131-178.

Kappeler PM (1990) The evolution of sexual size dimorphism in prosimian primates. Am. J. Primatol. 21: 201-214.
Kappeler PM (1991) Pattens of sexual size dimorphism in body weight among prosimian primates. Folia Primatol. 57:132-146.

Kay RF (1984) On the use of anatomical features to infer foraging behavior in extinct primates. In PS Rodman and JGH Cant (eds.): Adaptations for Foraging in Nonhuman Primates. Contributions to an Organismal Biology of Prosimians, Monkeys, and Apes. New York: Columbia University Press, pp. 21-53.

Kleiber N (1961) The Fire of Life. New York: J. Wiley and Sons.

Lumer H (1939) Relative growth of the limb bones in the anthropoid apes. Hum. Biol. 11:379-392.

Lumer H, and Schultz AH (1941) Relative growth of the limb segments and tail in macaques. Hum. Biol. 13:283-305.

Lumer H, and Schultz AH (1947) Relative growth of the limb segments and tail in Ateles geoffroyi and Cebus capucinus. Hum. Biol. 19:53-67.

McNaughton SJ, and Georgiadis NJ (1986) Ecology of African grazing and browsing mammals. Annu. Rev. Ecol. Syst. 17:39-65.

Meyers DM, and Wright PC (1993) Resource tracking: Food availability and Propithecus seasonal reproduc. tion. In PM Kappeler and JU Ganzhorn (eds.): Lemur Social Systems and Their Ecological Basis. New York: Plenum Press.

Oates JF, Whitesides GH, Davies AG, Waterman PG, Green SM, Dasilva GL, and Mole S (1990) Determinants of variation in tropical forest primate biomass: New evidence from West Africa. Ecology 71:328-343.

Overdorff DJ (1991) Ecological correlates of social structure in two prosimian primates: Eulemur fulvus rufus and Eulemur rubriventer. $\mathrm{PhD}$ thesis, Duke University.

Pereira ME (1993) Seasonal adjustment of growth rate and adult body weight in ringtailed lemurs. In PM Kappeler and JU Ganzhorn (eds.): Lemur Social Systems and Their Ecological Basis. New York: Plenum Press.

Ravosa MJ (1992) Allometry and heterochrony in extant and extinct Malagasy primates. J. Hum. Evol. 23:197-217.

Rensch B (1959) Evolution above the Species Level. New York: Columbia University Press.

Richard AF (1978) Behavioral Variation: Case Study of a Malagasy Lemur. Lewisburg: Bucknell University Press.

Richard AF (1985) Primates in Nature. New York: WH Freeman and Company.

Richard AF (1992) Aggressive competition between males, female-controlled polygyny and sexual monomorphism in a Malagasy primate, Propithecus verreauxi. J. Hum. Evol. 22:395-406.

Richard AF, and Nicoll ME (1987) Female social dominance and basal metabolism in a Malagasy primate, Propithecus verreauxi. Am. J. Primatol. 12:309-314.

Richard AF, Rakotomanga P, and Schwartz M (1991) Demography of Propithecus verreauxi at Beza Mahafaly, Madagascar: Sex ratio, survival, and fertility, 1984-1988. Am. J. Phys. Anthropol. 84:307-322.

Sailer LD, Gaulin SJC, Boster JS, and Kurland JA (1985) Measuring the relationship between dietary quality and body size in primates. Primates 26:14-27. 
Schmidt-Nielsen K (1972) Locomotion: Energy costs of swimming, flying and running. Science 177:222-228.

Schmidt-Nielsen K (1984) Scaling. Why Is Animal Size so Important? Cambridge: Cambridge University Press.

Shea BT (1981) Relative growth of the limbs and trunk in the African apes. Am. J. Phys. Anthropol. 56:179201.

Shea BT (1983) Allometry and heterochrony in the African apes. Am. J. Phys. Anthropol. 62:275-289.

Shea BT (1984) An allometric perspective on the morphological and evolutionary relationships between pygmy (Pan paniscus) and common (Pan troglodytes) chimpanzees. In RL Susman (ed.): The Pygmy Chimpanzee: Efvolutionary Biology and Behavior. New York: Plenum Press, pp. 89-130.

Shea BT (1988) Heterochrony in primates. In ML McKinney (ed.): Heterochrony in Evolution. New York: Plenum Press, pp. 237-266.

Shea BT (1992) Ontogenetic scaling of skeletal proportions in the talapoin monkey. J. Hum. Evol. 23:283307.

Sirnons EL (1988) A new species of Propithecus (Primates) from Northeast Madagascar. Folia Primatol. 50:143-151.

Sokal RR, and Rohlf FJ (1981) Biometry. New York: WH Freeman and Company.

Terborgh J (1983) Five New World Primates. A Study in Comparative Ethology. Princeton: Princeton University Press.

Terborgh J, and van Schaik CP (1987) Convergence vs. nonconvergence in primate communities. In JHR Gee and PS Giller (eds.): Organization of Communities Past and Present. Oxford: Blackwell Scientific Publications, pp. 205-226.

Waterman PG, Ross JAM, Bennett EL, and Davies AG
(1988) A comparison of the floristics and the leaf chemistry of the tree flora in two Malaysian rain forests and the influence of leaf chemistry on populations of colobine monkeys in the Old World Biol. J. Linn. Soc. 34:1-32.

APPENDIX A. Limb, trunk, and body weight measurements

Tail-crown length: tip of the tail to the anteriormost point on the head with the head in normal position (i.e., chin near the chest)

Tail length: tip of the tail to the ventral base of the tail at the perianal area

Body length: tail-crown length minus tail length

Chest circumference: transversely just caudal to the axilla

Forelimb length: axilla to the tip of the longest digit, excluding the nail

Forefoot length: proximal edge of the friction pad near the wrist to the tip of the longest digit, excluding the nail

Arm length: forelimb length minus forefoot length

Thumb length: junction between the first and second digits to the tip of the thumb, excluding the nail

Upper arm circumference ${ }^{1}$ : transversely just distal to the axilla

Hindlimb length: inguinal region to the tip of the longest digit, excluding the nail

Hindfoot length: heel to the tip of the longest digit, excluding the nail

Leg length: hindlimb length minus hindfoot length Big-toe length: junction between the first and second digits to the tip of the big toe, excluding the nail Thigh circumference ${ }^{1}$ : transversely just distal to the inguinal region

Body weight: in grams

${ }^{1}$ Data for upper arm circumference and thigh circumference are not available for either subspecies of Propithecus verreauxi. 